\title{
Article \\ A Novel Wearable Foot and Ankle Monitoring System for the Assessment of Gait Biomechanics
}

\author{
Paul Faragó ${ }^{1, *} \mathbb{C}$, Lăcrimioara Grama ${ }^{1} \mathbb{C}$, Monica-Adriana Farago ${ }^{2}$ and Sorin Hintea $^{1}$ \\ 1 Bases of Electronics Department, Electronics, Faculty of Telecommunications and Information Technology, \\ Technical University of Cluj-Napoca, 400114 Cluj-Napoca, Romania; Lacrimioara.Grama@bel.utcluj.ro (L.G.); \\ Sorin.HINTEA@bel.utcluj.ro (S.H.) \\ 2 Psycho-Neurosciences and Rehabilitation Department, Faculty of Medicine and Pharmacy, \\ University of Oradea, 410087 Oradea, Romania; monicafarago1959@gmail.com \\ * Correspondence: Paul.FARAGO@bel.utcluj.ro
}

Featured Application: A wearable monitoring system for the assessment of walking physiology.

Citation: Faragó, P.; Grama, L.;

Farago, M.-A.; Hintea, S. A Novel Wearable Foot and Ankle Monitoring System for the Assessment of Gait Biomechanics. Appl. Sci. 2021, 11, 268. https://doi.org/10.3390/ app11010268

Received: 29 November 2020 Accepted: 25 December 2020 Published: 29 December 2020

Publisher's Note: MDPI stays neutral with regard to jurisdictional clai$\mathrm{ms}$ in published maps and institutional affiliations.

Copyright: (C) 2020 by the authors. Licensee MDPI, Basel, Switzerland. This article is an open access article distributed under the terms and conditions of the Creative Commons Attribution (CC BY) license (https:// creativecommons.org/licenses/by/ $4.0 /)$.

\begin{abstract}
Walking is the most basic form of human activity for achieving mobility. As an essential function of the human body, the examination of walking is directed towards the assessment of body mechanics in posture and during movement. This work proposes a wearable smart system for the monitoring and objective evaluation of foot biomechanics during gait. The proposed solution assumes the cross-correlation of the plantar pressure with lower-limb muscular activity, throughout the stance phase of walking. Plantar pressure is acquired with an array of resistive pressure sensors deployed onto a shoe insole along the center of gravity progression line. Lower-limb muscular activity is determined from the electromyogram of the tibialis anterior and gastrocnemius lower limb muscles respectively. Under this scenario, physiological gait assumes the interdependency of plantar pressure on the heel area with activation of the tibialis anterior, as well as plantar pressure on the metatarsal arch/toe area with activation of the gastrocnemius. As such, assessment of gait physiology is performed by comparison of a gait map, formulated based on the footprint-lower-limb muscle cross-correlation results, to a reference gait template. A laboratory proof of concept validates the proposed solution in a test scenario which assumes a normal walking and two pathological walking patterns.
\end{abstract}

Keywords: EMG; resistive pressure sensor; footprint; center of pressure progression line; microcontroller; smart-shoe; cross-correlation; gait analysis; gait physiology; gait biomechanics

\section{Introduction}

Walking is the most basic form of human activity aimed for achieving mobility. As an essential function of the human body, examination and treatment procedures of walking are directed towards the preservation and restauration of good body mechanics in posture and in movement. Indeed, good body mechanics requires adequate joint range of motion, normal flexibility, a good neuro-muscular control, and even a good proprioception, all built on a good and healthy posture [1,2].

This paper is an extended version of our paper published in 2020 43rd International Conference on Telecommunications and Signal Processing (TSP) [1]. In the respective work, we have proposed a smart-shoe architecture based on an array of resistive pressure sensors and an electromyogram (EMG) acquisition frontend, aiming for gait monitoring in the context of activity. The extension of the smart-shoe architecture proposed in this paper targets the assessment of foot biomechanics during gait by cross-correlation of plantar pressures with corresponding lower-limb EMG signals. 
The studied literature, presented as follows, reveals that the framework for evaluating gait biomechanics is based on the plantar pressure distribution and on lower-limb EMG. Under this scenario, the context of our work targets the development of a wearable system for the acquisition of the plantar pressures along the center of pressure (COP) progression line and lower-limb EMG, in order to perform real-time gait monitoring and assessment in an automatic and autonomous fashion. The outcome of this paper is a laboratory proof of concept developed using off the shelf modules and validated in laboratory environment. The novelty of the proposed system consists in the underlying software application which evaluates the cross-correlation between the recorded plantar pressures and lower-limb EMG respectively, aiming to generate a gait map of the individual. As such, plantar pressures recorded with an array of force sensor resistances are cross-correlated to the lower-limb muscular activity extracted from the EMG signals. The cross-correlation results enable the formulation of a gait map which is employed for the assessment of physiological gait. Comparison of the generated gait map to a reference physiological gait map enables to discriminate physiological and pathological gait respectively.

The solution proposed in this work is envisioned in the shape of a wearable system, which performs both the monitoring and objective evaluation of foot biomechanics. The proposed approach for the objective evaluation of gait physiology is a novelty in the field.

The footprint is basically divided into three regions: forefoot (also accounting for the toes region), midfoot and heel, with the midfoot allowing a further divided into medial and lateral midfoot respectively $[3,4]$. The footprint accounts for ten anatomical areas which contribute to body weight support and body balance adjustment identified as: toe (1), lesser toes (2), metatarsophalangeal joints (3)-(7), midfoot (8), medial heel (9) and lateral heel (10), as illustrated in Figure 1 [5]. These anatomical areas are identified to contribute to body weight support and body balance adjustment. As such, assessment of ground reaction forces and pressures on these areas account for the derivation of lower-limb and whole-body physiological, structural and functional information [6,7].

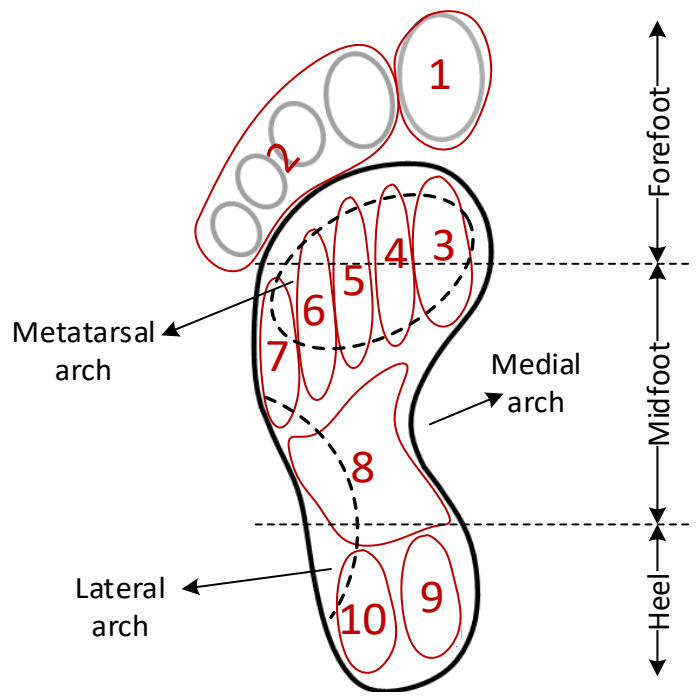

Figure 1. Representation of the footprint division into three regions: forefoot, midfoot and heel, with the illustration of the ten anatomical areas accountant for the derivation of lower-limb and whole-body physiological, structural and functional information.

The question which stands at this point targets the deployment of the pressure sensors in order to record the plantar pressure distribution for static, as well as dynamic assessment. Solutions proposed in literature for the static assessment of plantar ground forces assume several pressure sensor distributions presented as follows. A basic solution for the assessment of the body posture assumes three sensors for the forefoot, midfoot and heel respectively, as illustrated in Figure 2a [8]. A somewhat more complex solution was proposed by Shu et al., who deployed three sensors onto the midfoot and three sensors 
onto the heel area respectively, as illustrated in Figure 2b, [6]. It should be noted that the solution proposed by Shu et al. was also employed in walking tests. A different approach for sensor deployment was proposed by Elvitigala et al., as illustrated in Figure 2c, who envision two sensor clusters in the forefoot and heel area respectively, thus being able to estimate the center of pressure in each cluster respectively [9]. This solution was further aimed for plantar pressure assessment during training room exercises, namely squats and weightlifting.

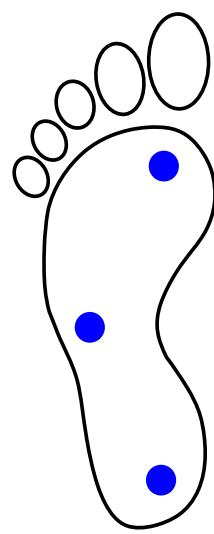

(a)

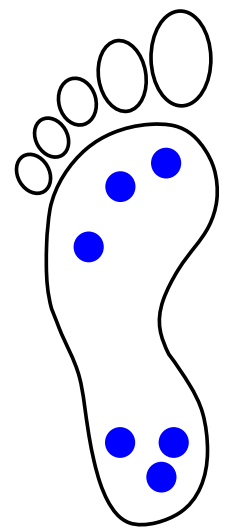

(b)

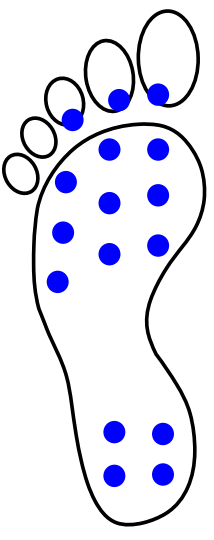

(c)

Figure 2. Solutions of pressure sensor deployment on the footprint for static assessment: (a) three sensors deployed onto the forefoot, midfoot and heel [8], (b) three sensors for the forefoot and heel respectively-this solution was also employed in walking tests [6], and (c) sensor arrays deployed on the forefoot and heel to estimate centers of pressure - this solution was also employed in training room exercise tests [9].

Walking is a cyclic pattern of movements, and as such, human walking analysis can be simplified by investigating one walking cycle-which is measured from the heel strike of one foot to the next heel strike of the same foot. One gait cycle consists of a stance and a swing phase respectively. The breakout of the gait cycle into six sequences is illustrated in Figure 3 for left leg (LL) stance. The left arm (LA) balance is also illustrated for clarity.

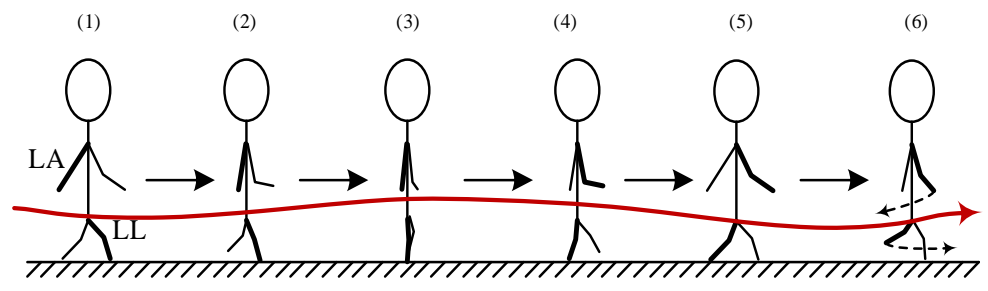

(a)
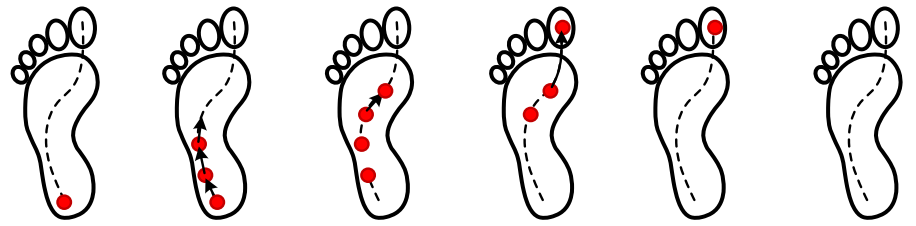

(b)

Figure 3. Breakout of a walking cycle for left leg (LL) stance into six sequences: (a) gait phases with the illustration of left arm (LA) balance and the oscillations of the body center of mass, (b) progression of the center of pressure with red circles indicating applied pressure. 
The sequences of the gait cycle account or heel strike (1), support, i.e., foot flat (2), midstance (3), heel off (4), toe-off (5) and swing (6). The average duration of one gait cycle ranges from 0.98 to $1.07 \mathrm{~s}$. The stance phase is the period that the foot is on the ground and accounts for approximately $60-62 \%$, i.e., 0.59 to $0.67 \mathrm{~s}$ of the gait cycle, during which the foot is weightbearing as the leg takes the bodyweight and provides a single leg support. The remaining $38-40 \%$, i.e., 0.38 to $0.42 \mathrm{~s}$ of one gait cycle is spent in the swing phase, which is the period of time that the foot is off the ground, moving forward and the limb advances [10,11].

During the gait cycle, pronation and supination normally occur in the foot segment. Pronation and supination are necessary for shock absorption and stability mechanisms for the healthy functioning of the feet and ankles. During the stance phase, the bodyweight travels along the foot, as indicated in Figure 3b illustrating the COP progression line. Physiological walking assumes that the weight moves inside and outside while the foot is rolling from the heel towards the toe. The pronation corresponds to the moment where the foot is in contact with the ground and begins to roll inward, everting slightly while the arch flattens. The purpose of the pronation is for the foot to be able to adapt to the surface. After the pronation, the foot continues towards supination. This results in the foot turning slightly outward then changing from a flexible foot to a more rigid foot, so it can propel the foot and push off from the ground. During this phase, the foot inverts slightly, and the arches become higher, thus enabling the foot to properly roll over the hallux [12]. As such, deviation from the physiological COP progression line accounts for some form of gait pathology. For illustration purpose, a physiological progression of the $\mathrm{COP}$ is presented in qualitative comparison to a pathological progression of the COP in Figure 4 .

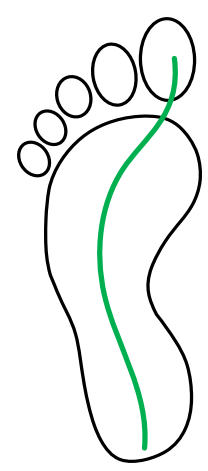

(a)

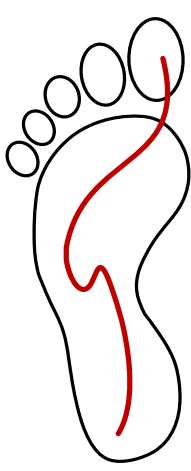

(b)

Figure 4. Center of pressure progression line for (a) physiological gait, (b) abnormal gait.

The COP progression line can be assessed very well with the pressure sensor distributions in Figure 2b,c. Nevertheless, a finer resolution in the acquisition of plantar pressures, which spans across the whole footprint, is achieved with sensor distributions presented as follows. Ivanov et al. deploys one sensor onto the toe, five sensors onto the metatarsal arch, one sensor onto the lateral arch and two sensors onto the heel [13], as illustrated in Figure 5a. As for another example, Cho et al. deploy only three sensors onto the metatarsal arch, three sensors onto the heel and an additional sensor onto the medial arch as an indicator of flat foot [14], as illustrated in Figure 5b. On the other hand, the solutions proposed by Aqueveque et al. in [15] and illustrated in Figure 5c, as well as the solution proposed by Kramer et al. in [16] and illustrated in Figure 5d, deploy an additional sensor onto the lesser toes. Additionally, the solution of Aqueveque et al. keeps the FSR on the medial arch for flat foot indication. 


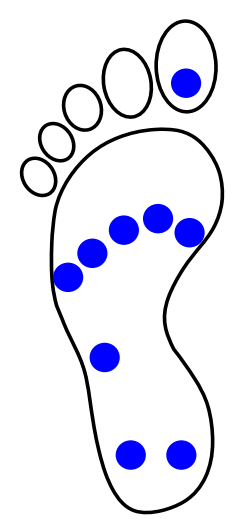

(a)

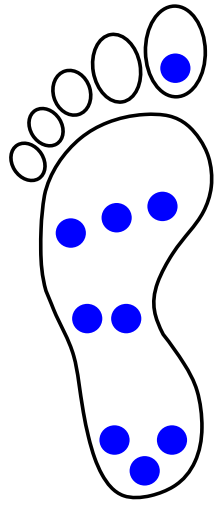

(b)

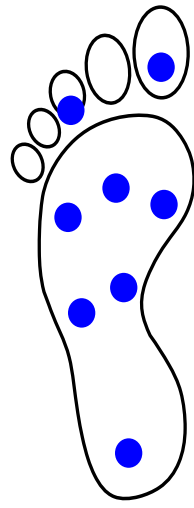

(c)

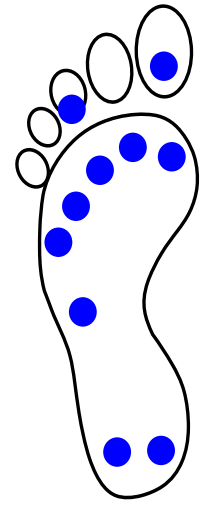

(d)

Figure 5. Solutions of pressure sensor deployment on the footprint for dynamic assessment: (a) assessment of the footprint medial line with sensors deployed onto the hallux, metatarsal arch, lateral arch and heel respectively [13], (b) additional sensor deployed on the medial arch for flatfoot identification [14], (c) additional sensor deployed on the lesser toes and medial arch for flatfoot identification [15], (d) additional sensor deployed on the lesser toes [16].

During walking, the foot is the first part of the lower extremity to contact the ground and has to face multiple force loads, ranging from external forces, e.g., gravitational attraction exerted by the Earth and to ground reaction forces (GRF), to internal forces, e.g., the body weight and the oscillations of body center of mass, as illustrated with the red line in Figure 3a.

The muscles involved in ankle movement are the pretibial muscles for dorsiflexion and calf muscles. The muscular activity for the lower kinetic chain throughout different phases of the gait cycle during the stance phase is listed in Table 1, followed by the muscular activity throughout the swing phase listed in Table 2.

Table 1. Muscular activity throughout the stance phases of the gait cycle [10].

\begin{tabular}{cccccc}
\hline Gait Phase & Heel Strike & Foot Flat & Midstance & Heel Off & Toe Off \\
\hline $\begin{array}{c}\text { Duration- } \\
\text { \% of } \\
\text { Total }\end{array}$ & $\mathbf{0 - 2} \%$ & $\mathbf{0 - 1 0 \%}$ & $\mathbf{1 0 - 3 0 \%}$ & $\mathbf{3 0 - 5 0 \%}$ & $\mathbf{5 0 - 6 0 \%}$ \\
\hline $\begin{array}{c}\text { Iliopsoas } \\
\text { Gluteus }\end{array}$ & inactive & inactive & inactive & concentric & concentric \\
Maximus & eccentric & inactive & inactive & inactive & inactive \\
$\begin{array}{l}\text { Gluteus } \\
\text { Medius }\end{array}$ & eccentric & eccentric & eccentric & eccentric & inactive \\
$\begin{array}{c}\text { Hamstrings } \\
\text { Quadriceps }\end{array}$ & eccentric & eccentric & inactive & inactive & inactive \\
Pretibial & eccentric & inactive & inactive & eccentric \\
muscles & eccentric & eccentric & inactive & inactive & inactive \\
Calf muscles & inactive & inactive & eccentric & concentric & concentric \\
\hline
\end{tabular}


Table 2. Muscular activity throughout the swing phases of the gait cycle [10].

\begin{tabular}{cccc}
\hline Gait Phase & Acceleration & Midswing & Deceleration \\
\hline Duration-\% of Total & $\mathbf{0 - 2} \%$ & $\mathbf{0 - 1 0 \%}$ & $\mathbf{1 0 - 3 0 \%}$ \\
\hline Iliopsoas & concentric & concentric & inactive \\
Gluteus Maximus & inactive & inactive & inactive \\
Gluteus Medius & inactive & inactive & inactive \\
Hamstrings & eccentric & eccentric & eccentric \\
Quadriceps & eccentric & inactive & inactive \\
Pretibial muscles & concentric & concentric & concentric \\
Calf muscles & inactive & inactive & inactive \\
\hline
\end{tabular}

In the present work, we have decided upon the assessment of the tibialis anteriorfrom the pretibial muscle group, and the gastrocnemius-from the calf muscle group. The tibialis anterior activity during the gait cycle is described as follows: eccentric contraction during heel strike; it continues to contract eccentrically during loading response (initial double limb support) to control plantar flexion moment; inactive during the remainder of the stance phase; and concentric contraction during the swing phase. The gastrocnemius muscle is active in most of the stance phase, initially in eccentric contraction and afterwards in concentric contraction. It acts mostly towards stabilizing the knee joint and controlling the fall of the center of mass during the single support phase of the gait [10,17].

The research of Qaqish et al., among others, studied the tibialis anterior during gait, investigating the muscular activity during the stance phase [18]. Lenhart et al. [19] and Orendurff et al. [20], among others, have studied the Gastrocnemius during gait.

The movement of one segment implies the balanced action of the agonist-antagonist muscles, e.g., flexors-extensors, abductor-adductors, internal-external rotators. Due to faulty posture and movements, as well as diseases, when the function of a muscular coupled with action on a specific joint is altered or unbalanced, one must take into account that there will be disfunctions in other joints of the kinetic chain as well. As far as gait is concerned, this implies all joints of the lower kinetic chain of the body, namely ankle, knee, hip and spine, and their muscles, namely calf muscles, pretibial muscles for the ankles, quadriceps, hamstring muscles for the knee, iliopsoas and gluteus maximus for the hip [10].

Our work is motivated by the fact that a series of body conditions can be inferred from foot biomechanics. For exemplification, the impact of foot position and foot posture on the body balance is assessed by Krewer et al. in [21] and Barati et al. in [22], indicating correlations with defective body posture. When considering normal posture, one looks for the proper alignment of the head and shoulders, the normal curves of the spine, the neutral posture of the pelvis, hips and knees and the $90^{\circ}$ angle of the ankle joints which are the first weight bearing joints implied in locomotion [2]. Additionally, numerous studies use foot posture as an indicator of the state of health. For exemplification, AlAbdulwahab et al. correlates foot posture index and core stability with the body mass index in the adult segment [23]. A similar study is presented by Aurichio et al. for the elderly segment [24]. Further correlation of foot posture to age and joint flexibility for children is discussed in [25].

Postural conditions further enable the analysis of locomotor dynamics, in terms of core stability, balance and sway $[22,26,27]$. Locomotion is the movement of the body by a coordinated series of muscle activities, in a particular direction, while the relation of the body as a whole to the ground is maintained. As such, based on the kinetic link principle, the human body can be regarded in terms of a series of interrelated links or segments. Movement of one segment affects both the proximal and the distal segments respectively [28].

As such, further considerations which motivate our work regard the integration of foot biomechanics and foot kinematics assessment into the analysis of locomotor patterns [29]. For the assessment of foot kinematics, the scientific literature proposes several models, the most employed being the three-segments Oxford foot model [30-32], the Rizzoli foot 
model [32,33], and the Heidelberg measurement method [32,34]. A comparison of the Oxford and the Rizzoli foot models considering normal gait and voluntarily pathological gait was conducted in [32,35], concluding that the kinematic output (both static and dynamic) of the Rizzoli foot model exhibits more informational content regarding plantar and dorsal flexion.

Regarding the employment of the plantar pressure distribution in the analysis the gait kinematics, Stebbins et al. studies the correlation between the plantar pressures and the Oxford foot model in [36]. On the other hand, Giacomozzi et al. studies and validates the anatomical masking of footprint pressures based on the Oxford foot model [37].

Regarding the employment of EMG assessment in conjunction with foot kinematics was reported by Wank et al. for treadmill running in [38] or by Prasad et al. for professional football players in [39].

To make our literature review more comprehensive, we present the studied literature in a comparative fashion in Table 3, listing a brief overview of the study, the number of participants involved in the study, the hardware used for data acquisition, the number of sensors for plantar pressure assessment, the availability of muscular activity assessment and a brief review of the results.

Table 3. Comparative presentation of the studied literature in a tabular form.

Results and Accuracy
As the speed increases $(1.5 \mathrm{~m} / \mathrm{s} \geq 2.5 \mathrm{~m} / \mathrm{s})$

The peak pressure of heel region increases about $33 \%$, in the medial arch about $16 \%$, in the lateral arch lift about $25 \%$, in the central forefoot about $19 \%$ and in the lateral forefoot about $18 \%$. The maximum force of the heel increases about $46 \%$, in the medial arch about $67 \%$, in lateral arch lift about $48 \%$, in the central forefoot about $23 \%$, in the lateral forefoot about $27 \%$, and in the medial forefoot lift about $17 \%$

As jogging slope increases $(0 \% \geq 15 \%)$

The peak pressure of heel decreases about $27 \%$, of the medial forefoot about $15 \%$, of the hallux about $26 \%$, and in the toes about $19 \%$
The intraclass correlation coefficient ICC > 0.86 for within-session walking trials, with all regions ICC $>0.8$ between-session, with all regions, apart from the lesser toes (0.79-left, 0.78-right) and midfoot (0.75-left, 0.76-right) The symmetry index (SI) showed a median range between $\sim 10-18 \%$ for the control group, while for the pathological group SI was between $~ 14-22 \%$

The symmetry angle (SA) showed a median range of $\sim 3-6 \%$ for the control group, while for the pathological group SA was between $\sim 4-7 \%$

\begin{tabular}{cll}
\hline Muscles & n.a. & n.a. \\
\hline No of Plantar Sensors & $85-99$ & 960 \\
\hline
\end{tabular}

8: (1) heel, (2) medial arch, (3) lateral arch, (4) medial metatarsal,

Plantar Data Regions

(5) central metatarsals, (6) lateral metatarsals, (7) great toe, and

(8) little toes 960

10: (1) interphalangeal joint (IPJ),

(2) lesser toes, (3)

metatarsophalangeal joint 1

(MPJ1), (4) MPJ2, (5) MPJ3; (6)

MPJ4, (7) MPJ5, (8) midfoot, (9) medial heel, and (10) lateral heel

F-scan in-shoe pressure measurement system (Tekscan, MA, USA)

51 (31 healthy and 20 with foot pathology)

No. of Participants 20 females

Ref. [4] compares the plantar pressure distribution of the foot

Reference between different incline and speed during treadmill jogging by using plantar insole measurement system
Ref. [5] identifies foot pathologies

based on plantar pressure

asymmetry 
Table 3. Cont.

\begin{tabular}{|c|c|c|c|}
\hline Results and Accuracy & $\begin{array}{l}\text { Visualizing CoP users were } \\
\text { able to improve their body } \\
\text { posture during squats and } \\
\text { dead-lift exercises } \\
\text { Squats for beginners } \\
\mathrm{F}_{3,168}=13.36, p<0.0001 \\
\text { Squats for advanced users } \\
\mathrm{F}_{3,168}=1.152, p>0.05 \\
\text { Dead-lifts } 10 \mathrm{~kg} \text { for beginners } \\
\mathrm{F}_{3,180}=10.66, p<0.0001 \\
\text { Dead-lifts } 10 \mathrm{~kg} \text { for advanced } \\
\text { users } \mathrm{F}_{3,157}=4.101, p<0.01 \\
\text { Dead-lifts } 20 \mathrm{~kg} \text { for beginners } \\
\mathrm{F}_{3,127}=12.47, p<0.0001 \\
\text { Dead-lifts } 20 \mathrm{~kg} \text { for advanced } \\
\text { users } \mathrm{F}_{3,144}=1.44, p>0.05\end{array}$ & $\begin{array}{l}\text { Features extracted: maximum, } \\
\text { minimum, mean, range, } \\
\text { zero-crossing rate, } \\
\text { root-mean-square values, } \\
\text { variance, standard variance, } \\
\text { skewness, and kurtosis } \\
\text { Classifier: Random forest } \\
\text { Classification accuracy: } \\
98.75 \% \text { ( } 80 \% \text { data training, } \\
20 \% \text { data testing, 5-fold cross } \\
\text { validation) }\end{array}$ & $\begin{array}{l}\text { Higher pressure values under the } \\
\text { forefoot were determined for } \\
\text { black participants when } \\
\text { compared with white }(\mathrm{t}=0.000, \\
p<0.05, \mathrm{~d}=0.78) \text { and coloured } \\
(\mathrm{t}=0.026, p<0.05, \mathrm{~d}=0.35) \\
\text { participants } \\
\text { Lower pressure values under the } \\
\text { midfoot region were obtained for } \\
\text { white participants compared with } \\
\text { black }(\mathrm{t}=0.003, p<0.05, \mathrm{~d}=0.94) \\
\text { and coloured }(\mathrm{t}=0.02, p<0.05, \\
\mathrm{d}=0.58) \text { participants }\end{array}$ \\
\hline Muscles & $\begin{array}{l}\text { Trapezius, spinal erectors, } \\
\text { gluteus maximus, adductor } \\
\text { magnus, hamstrings, } \\
\text { quadriceps femoris }\end{array}$ & n.a. & n.a. \\
\hline No of Plantar Sensors & $\begin{array}{l}16 \text { force-sensitive pressure } \\
\text { points, based on resistive } \\
\text { technology }+15 \text { markers (leg, } \\
\text { waist, shoulder) }\end{array}$ & $\begin{array}{l}9 \text { force sensors }+ \text { gyroscope }+ \\
\text { accelerometer }\end{array}$ & 10 \\
\hline Plantar Data Regions & $\begin{array}{l}\text { Plantar surface: anterior (12), } \\
\text { posterior }(4) \text { (sensors for } \\
\text { detecting CoP) }\end{array}$ & $\begin{array}{l}\text { 9: (1) the big toe (T1), }(2-6) \text { the } \\
\text { five metatarsal heads } \\
\text { (M1-M5), (7) the midfoot } \\
\text { (MF1), and (8-9)the heel (LH1, } \\
\text { MH1) }\end{array}$ & $\begin{array}{l}\text { 10: (1) the hallux (great toe), ( } 2) \\
\text { lateral toes, ( } 3-7) \text { metatarsal 1-5, } \\
\text { (8) midfoot, (9) medial heel, and } \\
\text { (10) lateral heel }\end{array}$ \\
\hline $\begin{array}{l}\text { Hardware Used for Data } \\
\text { Collection }\end{array}$ & $\begin{array}{l}\text { GymSoles prototype, placed } \\
\text { on both feet }+ \text { an OptiTrack } \\
\text { motion tracking system }\end{array}$ & n.a. & $\begin{array}{l}\text { RS Footscan (RSscan, Belgium) } \\
\text { system was used to measure the } \\
\text { plantar pressure values of the foot }\end{array}$ \\
\hline No. of Participants & 13 (9 males and 4 females) & 20 & $\begin{array}{l}180 \text { (gender: } 90 \text { male, and } 90 \\
\text { female; race: } 60 \text { black, } 60 \text { white, } \\
\text { and } 60 \text { coloured) }\end{array}$ \\
\hline
\end{tabular}

Ref. [13] presents a multimodal sensor insole that allows capturing kinetic and kinematic information reflecting the foot dynamic characteristics, for person recognition
Ref. [9] describes a way to

Reference improve the body posture by visualizing the center of pressure (CoP)
The instants of foot off (FO) and foot contact (FC) with respect to the onset of the movement $(\mathrm{t} 0)$ did not change with added load The onset of SOL activity with respect to FO was significantly anticipated in the loaded trials $(\mathrm{F}(1,9)=5.183, p<0.05)$; velocity per se had no significant effect $(\mathrm{F}(1,9)=0.01, p=0.92)$ No significant difference in the time of onset across the three muscle bursts (SOL, GM and GL) $(\mathrm{F}(2,6)=0.96, p=0.40)$ The propulsive force increased on average by about $36 \%$ for the spontaneous velocity $(\mathrm{F}(1,9)=101.1, p<0.001)$, and by about $29 \%$ for the fast velocity $(\mathrm{F}(1,9)=8.1, p<0.05)$

The grand mean value of the gap measured at FC was the same between no-load and load conditions, at both spontaneous $(\mathrm{F}(1,9)=0.0002, p=0.98)$ and fast velocity $(\mathrm{F}(1,9)=1.74, p=0.22)$ The grand mean value of the torque was significantly larger under the loaded condition, both for the spontaneous $(\mathrm{F}(1,9)=9.92$, $p<0.05)$ and for the fast velocity $(\mathrm{F}(1,9)=163.98, p<0.001)$
There was no correlation between the total muscle activity during stance phase and navicular drop $(\mathrm{r}=00.046, p=0.816)$, age $(\mathrm{r}=0.024, p=0.902)$ and weight $(\mathrm{r}=0.163, p=0.408)$
Ref. [16] presents generation of normative tables from plantar pressure data
Results and accuracy 
Table 3. Cont.

\begin{tabular}{cll}
\hline \multicolumn{1}{c}{ Muscles } & $\begin{array}{l}\text { triceps surae muscle, gastrocnemius medialis, gastrocnemius } \\
\text { lateralis }\end{array}$ & tibialis anterior \\
\hline No of Plantar Sensors & 5 & 2 \\
\hline Plantar Data Regions & $\begin{array}{l}\text { 5: (1-2) right and left tibialis anterior (TA), (3) soleus (SOL), (4) } \\
\text { gastrocnemius medialis (GM), and (5) gastrocnemius lateralis } \\
\text { (GL) muscles }\end{array}$ & n.a. \\
\hline
\end{tabular}
(GL) muscles

Hardware Used for Data
Collection

No. of Participants

10 ( 1 female, and 9 males)
A large force platform ( $0.90 \mathrm{~m} 61.80 \mathrm{~m}$, AMTI, USA) was used to record ground reaction force and moments. Surface EMG activity was recorded using bipolar $\mathrm{Ag}$ - $\mathrm{AgCl}$ electrodes $(8 \mathrm{~mm}$ diameter, $20 \mathrm{~mm}$ inter-electrode distance) n.a.

28 (9 females, and 8 males; foot type: 10 normal, 10 pronated, and 8 supinated)

Ref. [18] presents tibialis anterior muscle electromyography (EMG) activity during stance phase of gait

There was a significant difference in toe-out position between the different conditions $(\mathrm{F}(4,92)=12.833, p=0.000$, $\left.\eta^{2}=0.358\right)$.

Individual distances of self-selected foot position positively correlated with participants' body height $(\mathrm{r}=0.631, p=0.001)$ Significant effect of different foot positions between several conditions for the static and dynamic trials were observed For the medio-lateral sway: static $(\mathrm{F}(2.805,64.511)=24.820$, $\left.p=0.000, \eta^{2}=0.519\right)$, dynamic $(\mathrm{F}(2.998,65.037)=32.349$, $p=0.000, \eta^{2}=0.595$ )

For the antero-posterior sway: static $(\mathrm{F}(5,115)=3.150, p=0.011$, $\left.\eta^{2}=0.120\right)$, dynamic $(\mathrm{F}(2.713$, $59.697)=14.421, p=0.003$, $\left.\eta^{2}=0.396\right)$

\begin{tabular}{ll}
\hline Muscles & gastrocnemius or soleus \\
\hline & 44 reflective surface markers were used to track and record 3D
\end{tabular}
n.a. whole-body kinematics: 25 on anatomical landmarks

No of Plantar Sensors 14 on rigid plates strapped to the shanks and thighs Pre-amplified, single differential EMG electrodes (DE-2.1, n.a. DelSys Inc., Boston, MA, USA) were placed over the medial and lateral gastrocnemius, soleus, tibialis anterior, vastus medialis, and medial hamstrings 
Table 3. Cont.

\begin{tabular}{|c|c|c|c|}
\hline $\begin{array}{l}\text { Hardware Used for Data } \\
\text { Collection }\end{array}$ & \multicolumn{2}{|l|}{ n.a. } & $\begin{array}{l}\text { Posturographic measurements } \\
\text { were recorded by a piezoelectric } \\
\text { force plate }\end{array}$ \\
\hline No. of Participants & \multicolumn{2}{|l|}{20} & 24 (14 females, and 10 males) \\
\hline Reference & \multicolumn{2}{|c|}{$\begin{array}{l}\text { Ref. [19] illustrates the effect of electrically stimulating the } \\
\text { gastrocnemius or soleus at different stages of the gait cycle }\end{array}$} & $\begin{array}{l}\text { Ref. [21] describes the effects of } \\
\text { different foot positions on static } \\
\text { and dynamic standing balance to } \\
\text { develop recommendations for } \\
\text { posturographic protocol }\end{array}$ \\
\hline Results and Accuracy & \multicolumn{2}{|l|}{$\begin{array}{l}\text { Footprint indices: anterior } \\
\text { area }(\mathrm{F}=6.29, p=0.21), \mathrm{mid} \\
\text { area }(\mathrm{F}=4.17, p=0.055), \\
\text { posterior area }(\mathrm{F}=16.5 \\
p=0.01), \text { total area }(\mathrm{F}=9.97, \\
p=0.005), \text { arch index } \\
(\mathrm{F}=0.015, p=0.903) \\
\text { Balance indices: } \\
\text { posterior-lateral }(\mathrm{F}=3.97 \\
p=0.61), \text { posterior-medial } \\
(\mathrm{F}=0.55, p=0.467), \text { anterior } \\
(\mathrm{F}=8.74, p=0.008), \text { total } \\
(\mathrm{F}=4.32, p=0.051)\end{array}$} & $\begin{array}{l}\text { Higher FPI was associated } \\
\text { moderately with higher Beighton } \\
\text { score }(\mathrm{r}=0.44, p=0.01) \\
\text { Greater lunge angle was } \\
\text { associated moderately with } \\
\text { higher Beighton score }(\mathrm{r}=0.40, \\
p=0.02) \text { and Lower Limb } \\
\text { Assessment Scale score (LLAS) } \\
(\mathrm{r}=0.42, p=0.02) \\
\text { Higher Beighton score was } \\
\text { associated strongly with higher } \\
\text { LLAS ( } \mathrm{r}=0.85, p<0.01) \\
\text { ICC }>0.85 \text { (mean } 95 \% \mathrm{CI} \\
0.86-0.97)\end{array}$ \\
\hline Muscles & n.a. & n.a. & n.a. \\
\hline No of Plantar Sensors & n.a. & n.a. & n.a. \\
\hline Plantar Data Regions & $\begin{array}{l}\text { Anterior, mid, and posterior } \\
\text { areas of footprint }\end{array}$ & n.a. & n.a. \\
\hline
\end{tabular}

\section{Hardware Used for Data Collection}

static footprint, without toes

Foot biomechanics were analyzed using the FPI. CS was assessed using a plank test with a time-to-failure trial

No. of Participants

22 (11 normal, and 11
overweight)

Ref. [22] compares balance

Reference and footprint parameters for normal and overweight children

\section{9}

Ref. [23] investigates the effect of the body mass index (BMI) on the foot posture index (FPI) and core stability (CS) in a healthy adult population. n.a.

30 (20 girls, and 10 boys)

Ref. [25] explores the relationships between foot posture, flexibility, body mass and age in children coefficient of multiple correlation (CMC) is 0.614 for tibia with respect to the floor inter-segment angle $\mathrm{CMC}=0.974:$ hallux with respect to the forefoot plantar/dorsiflexion overall between-trial

Results and Accuracy variability $< \pm 1.0^{\circ}$ (for 10 foot parameters), and $< \pm 0.7^{\circ}$ (for hindfoot with respect to the tibia and forefoot with respect to the hindfoot) tibia with respect to the floor inter-segment angle between-trial variability was between $\pm 1^{\circ}$ and $\pm 2^{\circ}$
Intraclass correlation coefficients (ICC) ranged from 0.020 to 0.964 for between-day reliability

ICC ranged from 0.268 to 0.985 for within-session The standard error measurement (SEM) range was between 0.04 to 3.5 and the root mean squared error (deviation) ranged from 0.73 to 16.2 degrees
12 foot parameters are evaluated - stride-to-stride coefficient of multiple correlation $(\mathrm{CMC})>0.8$ (for all 12);

- day-to-day CMC > 0.8 (for 6 foot parameters: Tibio-talar-flexion,

Medial arch inclination,

Forefoot/ankle supination, Forefoot/ankle abduction, MT I-V angle, Hallux flexion) and $<0.7$ (for the other 6: Medial arch, Lateral arch, Subtalar inversion, Fore-/midfoot supination, Fore-/hindfoot abduction, Hallux abduction) 
Table 3. Cont.

\begin{tabular}{|c|c|c|c|}
\hline Muscles & n.a. & n.a. & n.a. \\
\hline No of Plantar Sensors & 19 & $\begin{array}{l}29 \text { passive reflective markers } \\
14 \mathrm{~mm} \text { in diameter, attached } \\
\text { directly on the skin }\end{array}$ & $\begin{array}{l}\text { Seventeen } 14 \mathrm{~mm} \text { diameter } \\
\text { retro-reflective markers were } \\
\text { attached to the skin on each leg }\end{array}$ \\
\hline Plantar Data Regions & $\begin{array}{l}3 \text { segment foot model } \\
\text { (hindfoot, forefoot and hallux) } \\
+ \text { tibial segment }\end{array}$ & $\begin{array}{l}\text { 4: shank, hindfoot, forefoot } \\
\text { and hallux segments }\end{array}$ & n.a. \\
\hline $\begin{array}{l}\text { Hardware Used for Data } \\
\text { Collection }\end{array}$ & n.a. & $\begin{array}{l}\text { New Balance neutral } \\
\text { cushioning shoe (model } 840 \text { ) } \\
\text { with circular holes cut out } \\
\text { with a diameter of } 2.5-2.7 \mathrm{~cm}\end{array}$ & n.a. \\
\hline No. of Participants & 2 & 12 & 10 (4 males, and 6 females) \\
\hline Reference & $\begin{array}{l}\text { Ref. [30] presents the } \\
\text { evaluation of foot kinematics } \\
\text { during barefoot walking } \\
\text { based on a multi-segment foot } \\
\text { model ( } 12 \text { foot parameters are } \\
\text { evaluated) }\end{array}$ & $\begin{array}{l}\text { Ref. [31] investigates the } \\
\text { between-day reliability and } \\
\text { within-session variability of } \\
\text { the Oxford Foot Model (OFM) } \\
\text { while walking in a neutral } \\
\text { cushioning shoe }\end{array}$ & $\begin{array}{l}\text { Ref. [34] a protocol for measuring } \\
\text { the kinematics of the foot and } \\
\text { ankle ( } 12 \text { foot parameters are } \\
\text { evaluated) }\end{array}$ \\
\hline Results and Accuracy & \multicolumn{3}{|c|}{ No numerical values available, only graphs } \\
\hline Muscles & \multicolumn{3}{|l|}{ n.a. } \\
\hline No of Plantar Sensors & \multicolumn{3}{|l|}{21 six $\mathrm{mm}$ retroreflective markers } \\
\hline Plantar Data Regions & \multicolumn{3}{|c|}{$\begin{array}{l}\text { number of foot segments that comprise the foot for each model } \\
\text { varies (all } 5 \text { models, however, contain equivalent hindfoot, } \\
\text { forefoot, and hallux segments) }\end{array}$} \\
\hline $\begin{array}{l}\text { Hardware Used for Data } \\
\text { Collection }\end{array}$ & \multicolumn{3}{|l|}{ n.a. } \\
\hline No. of Participants & \multicolumn{3}{|l|}{10 (6 males, and 4 females) } \\
\hline Reference & \multicolumn{3}{|c|}{$\begin{array}{l}\text { Ref. [35] compares the repeatability and kinematics of five } \\
\text { different three-dimensional multi-segmented foot models }\end{array}$} \\
\hline
\end{tabular}

\section{Materials and Methods}

This work proposes a wearable monitoring system for the assessment of gait biomechanics. Objective evaluation if performed in terms of correlation of the plantar pressure distribution along the footprint, recorded along the COP progression line, and lower-limb EMG. The block diagram of the proposed solution is illustrated in Figure 6 and is explained as follows.
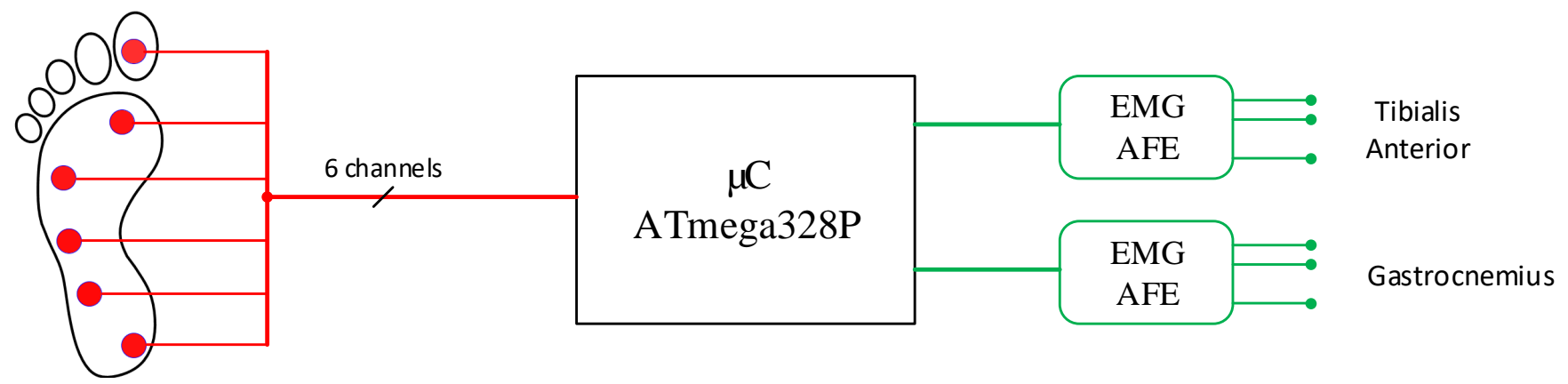

Figure 6. Block diagram of the proposed wearable foot biomechanics monitoring system. 
An ATmega328P microcontroller $(\mu \mathrm{C})$, deployed on an Arduino Nano board, is employed to read six Aidong IMS C20B thin-film resistive sensors deployed onto a shoe insole. Next, the $\mu \mathrm{C}$ performs the acquisition of two EMG channels via off the shelf Mikroelektronika EMG Click analog front ends (AFE). Signal acquisition is performed with a $f_{S_{-} F S R}=100 \mathrm{~Hz}$ sampling frequency for the plantar pressures and a $f_{S_{-} E M G}=1 \mathrm{kHz}$ sampling frequency for the EMG channels respectively. A synchronized sampling method was adopted, having one analog input channel for each targeted signal. Resolution of the acquired signals is given by the 10-bit analog to digital converter (ADC).

The wearable foot biomechanics monitoring system laboratory proof of concept is illustrated in Figure 7. The electronics, i.e., Arduino Nano board with ATmega328P $\mu$, pressure sensor circuit breadboard and two EMG acquisition AFEs, were attached onto a Velcro strip, as illustrated in Figure 7a, to enable wearing on the lower limb, as illustrated in Figure $7 b$.

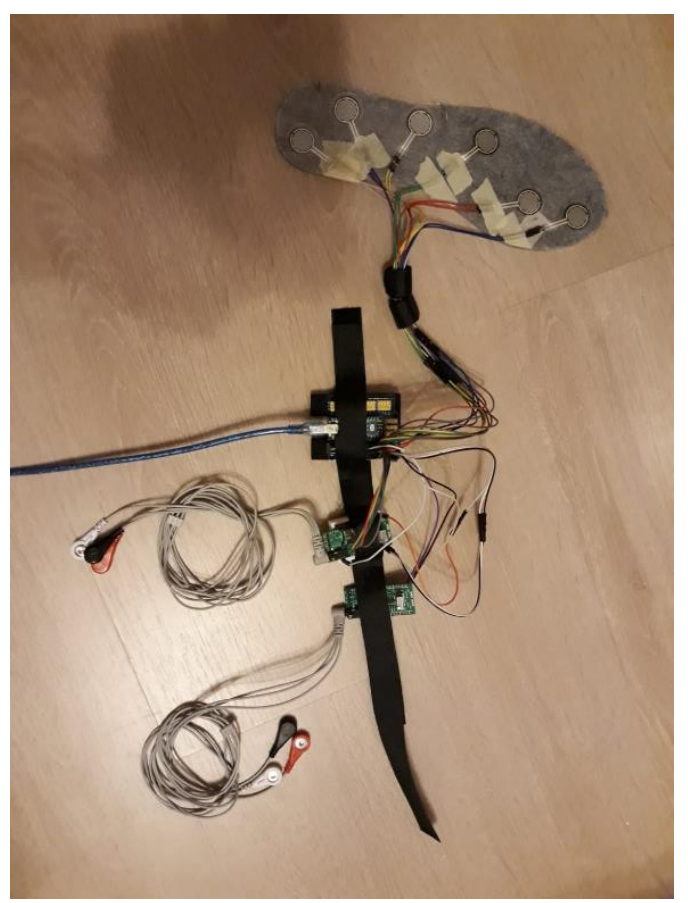

(a)

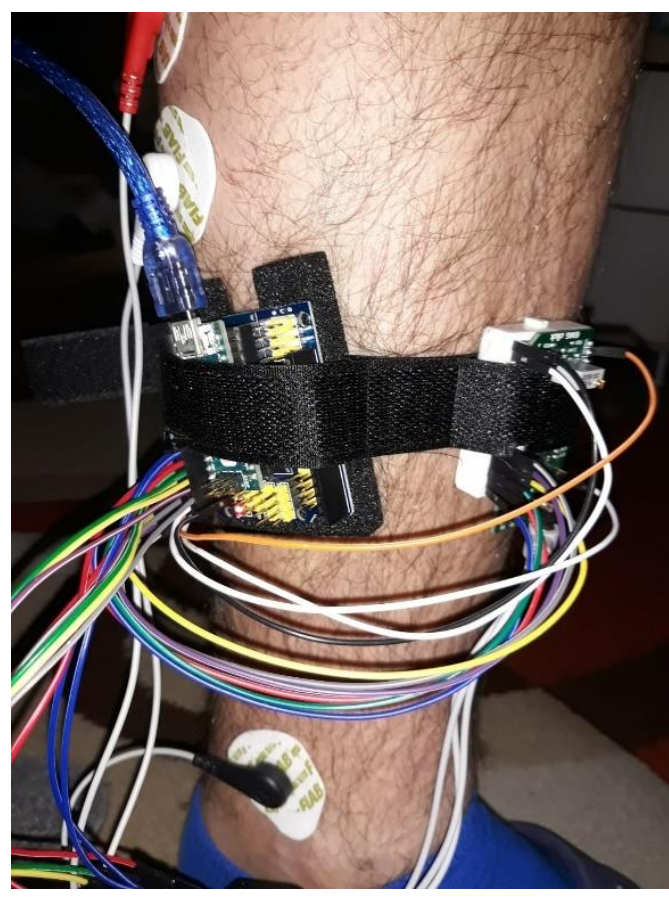

(b)

Figure 7. The wearable foot biomechanics monitoring system laboratory proof of concept: (a) circuit setup, (b) system wearing on the lower limb.

The pressure sensor and EMG signal acquisition and processing follows the logical diagram illustrated in Figure 8, aiming for the identification of physiological gait. As illustrated, the first stage is the acquisition of plantar pressures and lower-limb EMG signals. At this stage, it is possible to visualize the recorded signals in time-domain using the Arduino Studio Plotter or Monitor. From this point on, processing is twofold. On one hand, EMG signal processing accounts for feature extraction, activity discrimination and extraction of muscular activity. On the other hand, processing of the pressure signals account for the identification of sensor activation-which enables the visualization of the COP progression line in Processing. Finally, cross-correlation of the muscular activity with the plantar pressures is aimed to testing and validating the physiology of gait. 


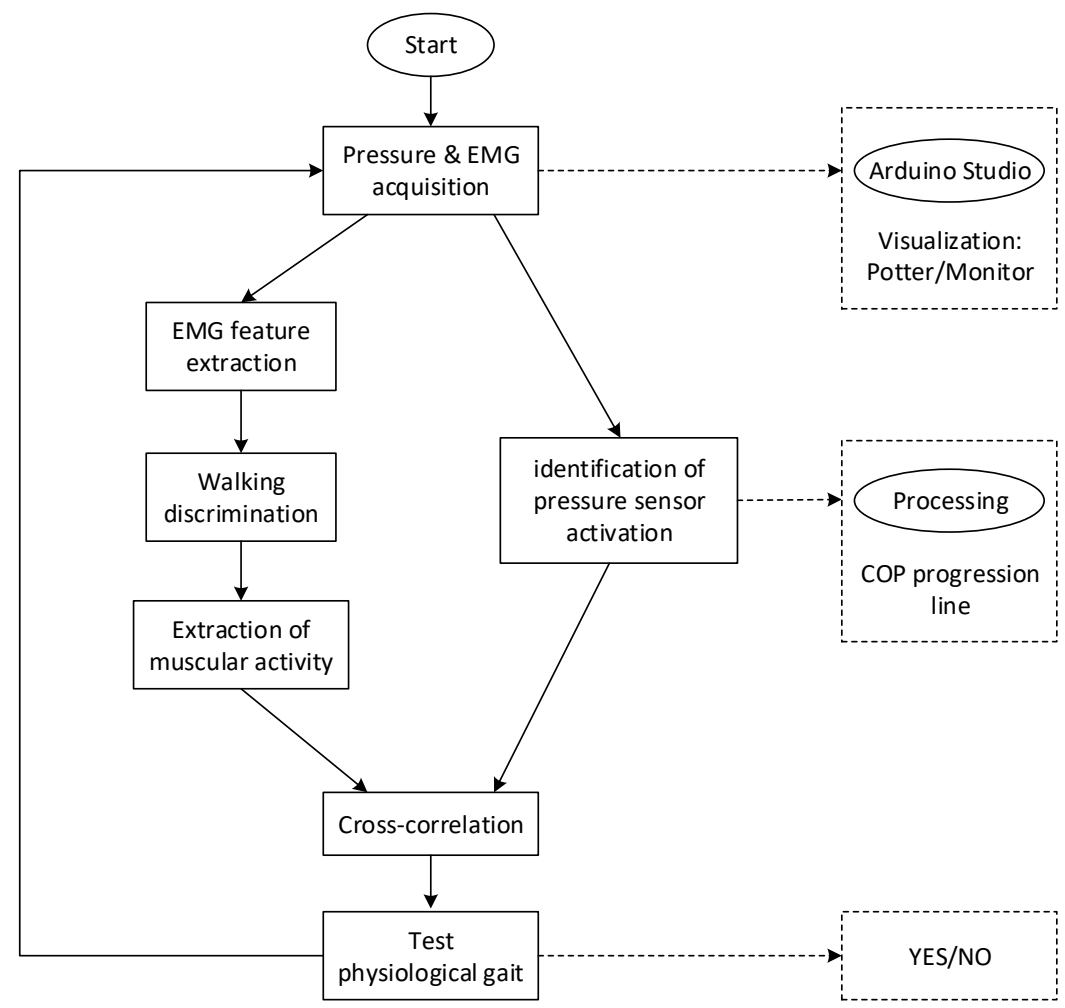

Figure 8. Logical diagram of the wearable foot biomechanics monitoring system software.

\subsection{Plantar Pressures Ssessment}

In this work, we have performed plantar pressure assessment with six Aidong IMS C20B thin-film resistive sensors operating as force sensor resistors (FSR), deployed as illustrated in Figure 9a: one sensor on the hallux $\left(\mathrm{FSR}_{0}\right)$, two sensors on the metatarsal arch $\left(F_{1}\right.$ and $\left.F S R_{2}\right)$, two sensors on the lateral arch $\left(\mathrm{FSR}_{3}\right.$ and $\left.\mathrm{FSR}_{4}\right)$, and one sensor on the heel area $\left(\mathrm{FSR}_{6}\right)$. Our aim for this sensor deployment was to follow the COP progression line of normal gait. The practical realization of the resistive pressure sensor array is then depicted in Figure 9b.

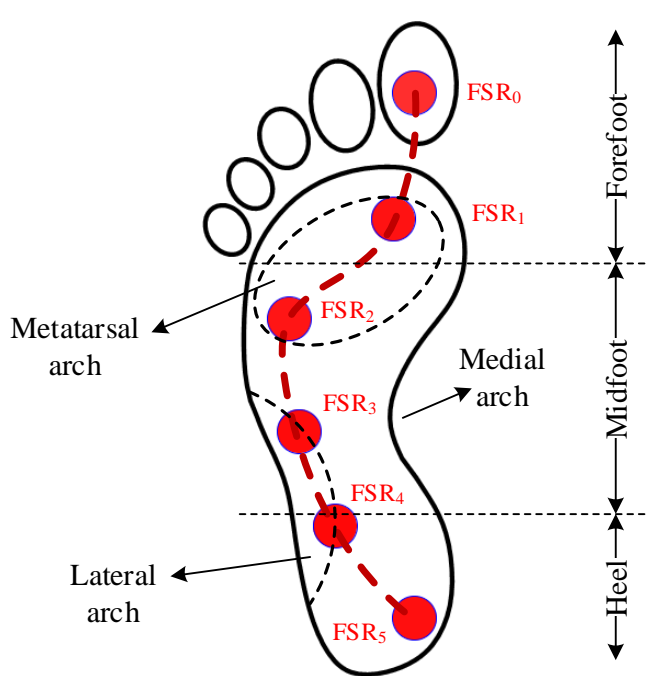

(a)

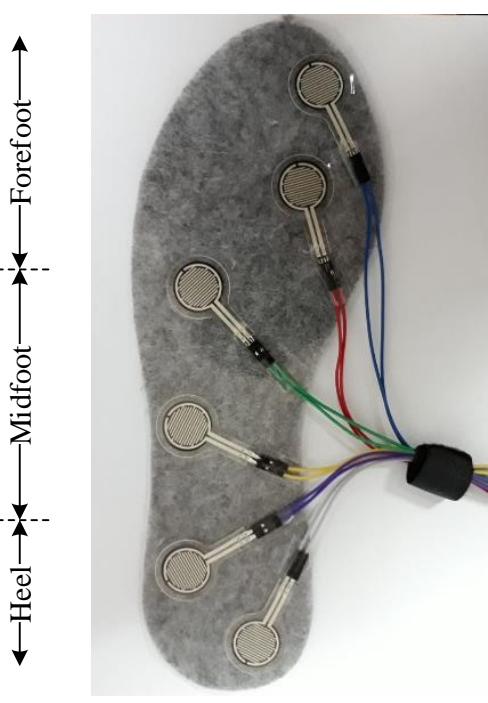

(b)

Figure 9. Proposed pressure sensor deployment along the COP progression line for plantar pressure assessment: (a) diagram, (b) practical realization. 
An FSR is deployed in a resistive divider connection with a grounded $1 \mathrm{M} \Omega$ resistance $R$. The FSR resistance is then derived from the voltage divider law as

$$
F S R=\left(\frac{V_{C C}}{V_{R}}-1\right) \cdot R
$$

where $V_{C C}$ is the supply voltage and $V_{R}$ is the $1 \mathrm{M} \Omega$ resistance voltage drop.

The resistance voltage drops were read with the ATmega328P $\mu \mathrm{C}$ with a $f_{S_{-} F S R}=100 \mathrm{~Hz}$ sampling frequency and, after filtering with a second-order $f_{C_{-} F S R}=35 \mathrm{~Hz}$ cutoff frequency Butterworth lowpass filter for noise removal [1,26], the FSR resistance values were determined according to (1).

\subsection{Lower-Limb EMG Assessment}

Electrode placement for the left-leg lower-limb EMG monitoring is depicted in Figure 10a for the Tibialis anterior with the reference electrode placed above the lateral malleolus, and in Figure $10 \mathrm{~b}$ for the gastrocnemius with the reference electrode placed above the medial malleolus.

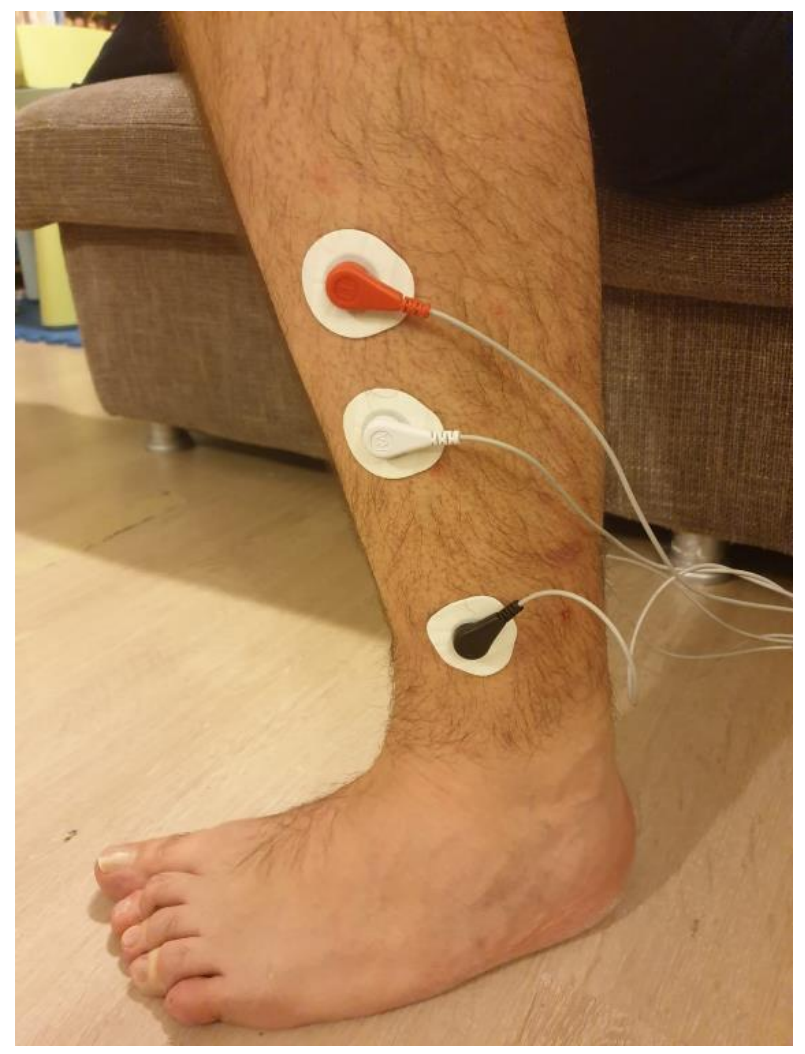

(a)

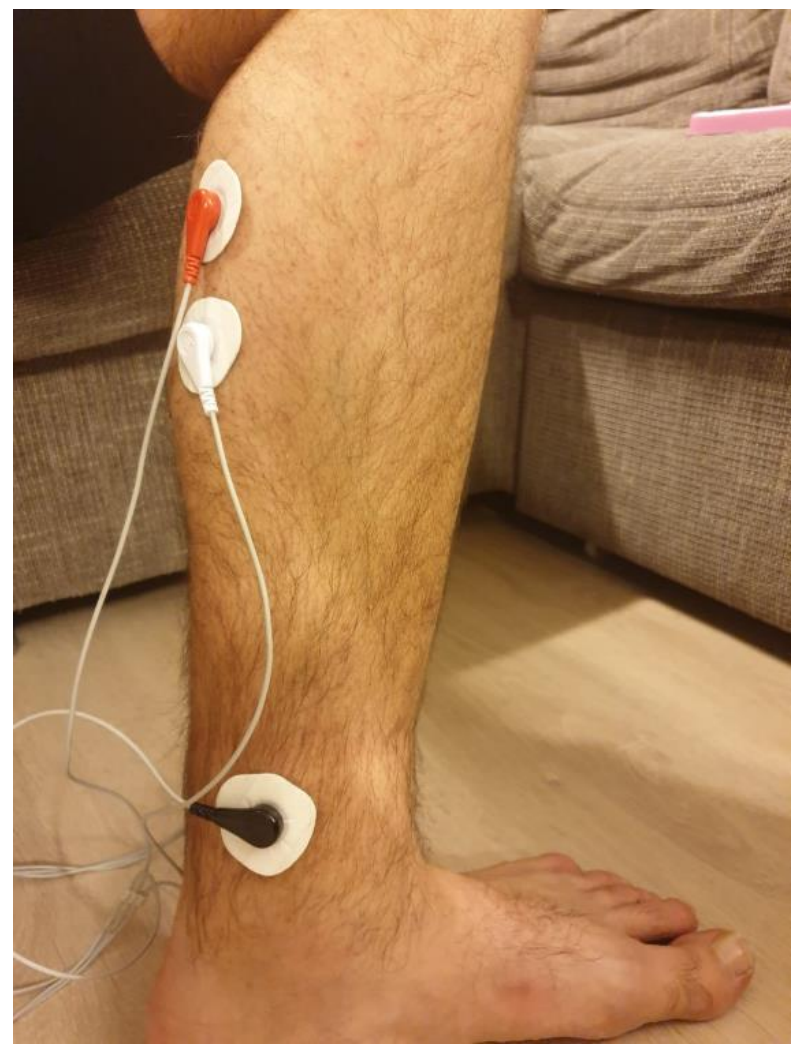

(b)

Figure 10. Electrode placement for lower-limb EMG acquisition of the (a) tibialis anterior, (b) gastrocnemius.

Acquisition of an EMG channel was performed with a $f_{s_{-} E M G}=1 \mathrm{kHz}$ sampling frequency using $\mathrm{Ag} / \mathrm{AgCl}$ wet electrodes and the Mikroelektronika EMG Click board. As specified in the AFE datasheet, signal acquisition follows two on-board gain stages, i.e., instrumentation amplifier and variable gain amplifier, implemented with a MPC609 operational amplifier and MAX6106 micropower voltage reference, and three analog filter stages, i.e., high-pass filter with $1.6 \mathrm{~Hz}$, and $0.16 \mathrm{~Hz}$ cutoff frequencies respectively and lowpass filter with $60 \mathrm{~Hz}$ cutoff frequency [40].

The EMG signal is nominally in the $1 \mu \mathrm{V}-10 \mathrm{mV}$ amplitude range [41,42], with signal amplitudes accounting as follows. The motor unit action potential (MUAP) of a healthy 
muscle ranges around $2 \mathrm{mV}$ in amplitude, primary muscular disease accounts for MUAPs around $0.5 \mathrm{mV}$, whereas re-innervation and intramuscular sprouting of chronic partial denervation results in MUAPs larger than $10 \mathrm{mV}$ [43]. As such, the AFE gain of the EMG acquisition board was set to $10 \mathrm{x}$ such as to have the EMG signal in the +/ $50 \mathrm{mV}$ amplitude range prior to ADC.

After acquisition, EMG feature extraction was aimed towards the determination of muscular activity and muscle activation patterns. Information regarding muscular activity is retained in the lower frequency range below $50 \mathrm{~Hz}$. Time-domain features regarding the muscle activation pattern on the other hand are available in the $500 \mathrm{~Hz}$ frequency band [44-46]. For this purpose, the EMG signal is applied to a bank of two parallel filter as illustrated in Figure 11. However, it should be noticed that $150 \mathrm{~Hz}$ lowpass filtering was considered for the muscle activation pattern as we were interested in the identification of the muscle activation pattern rather than its assessment. After filtering, segmentation of the ECG signal is performed with 128-sample non-overlapping adjacent rectangular windows [47].

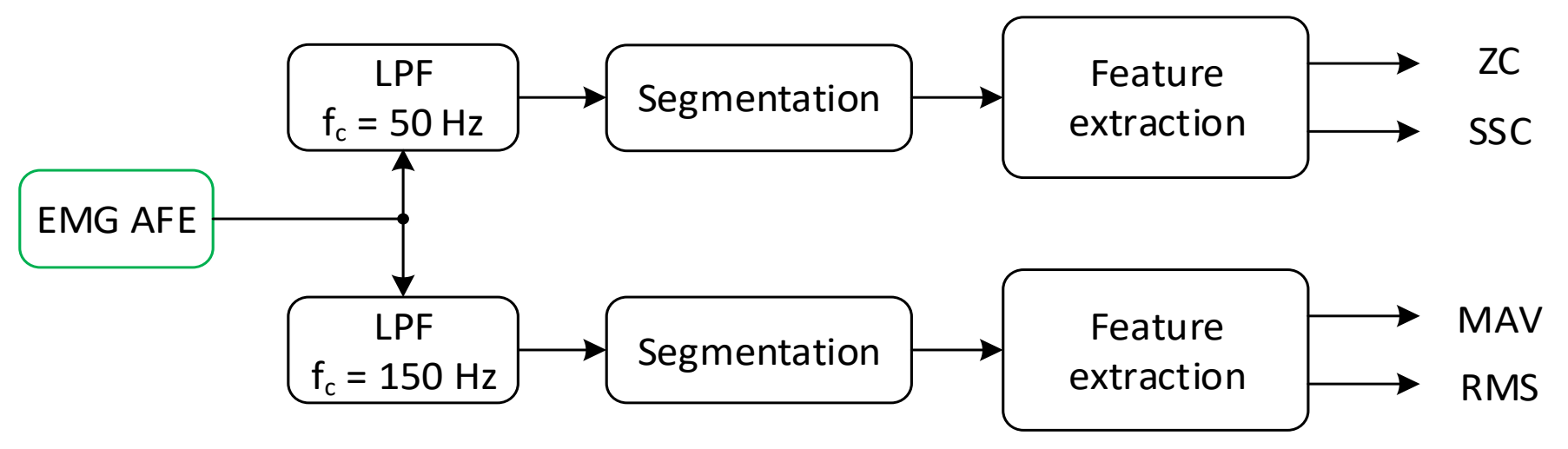

Figure 11. Block diagram of the EMG feature extraction procedure assuming two parallel lowpass filters: $50 \mathrm{~Hz}$ lowpass filter for muscular activity and $150 \mathrm{~Hz}$ for the muscle activation pattern.

Further on, the features of interest in this work are presented. Features of muscular activation are extracted from the ECG signal limited to the $50 \mathrm{~Hz}$ bandwidth in terms of the zero crossing (ZC) and slope sign changes (SSC) count defined as:

$$
Z C=\sum_{i=2}^{N}\left(\operatorname{sgn}\left(x_{i-1} \cdot x_{i}\right)=-1\right),
$$

and

$$
S S C=\sum_{i=3}^{N}\left(\operatorname{sgn}\left(\left(x_{i-1}-x_{i-2}\right) \cdot\left(x_{i}-x_{i-1}\right)\right)=-1\right),
$$

where $N$ is the segment length. The $\mathrm{ZC}$ expressed by (2) is a measure of the signal sign changes, namely the number of times the signal crosses the zero axis. As such, a large ZC count accounts for small signal swing, i.e., low muscular activity, whereas a small ZC count accounts for large signal swing, i.e., high muscular activity. Similarly, the SSC expressed by (3) is a measure of the local extrema, namely the number of changes from a positive slope to a negative slope (local maxima), or from a negative slope to a positive slope (local minima). As such, a large SSC count accounts for small signal swing, i.e., low muscular activity, whereas a small SSC count accounts for large signal swing, i.e., high muscular activity. Both ZC and SSC can be accounted for as an indicator for the onset of movement $[48,49]$.

Features of the muscle activation pattern are extracted from the ECG signal limited to the $150 \mathrm{~Hz}$ bandwidth in terms of the mean absolute value (MAV) and root mean square (RMS) defined as: 


$$
M A V=\frac{1}{N} \sum_{i=1}^{N}\left|x_{i}\right|,
$$

and

$$
R M S=\sqrt{\frac{1}{N} \sum_{i=1}^{N} x_{i}^{2}} .
$$

The MAV expressed by (4) estimates the baseline during muscular activity [49], which in the present work accounts for lower-limb motion. The RMS expressed by (5) on the other hand is regarded as an estimator of the signal energy content and, as such, is employed as a measure of muscular activity [44]. Both MAV and RMS can be accounted for as an indicator for intensity.

It should be noticed that we restrict the feature extraction procedure in this work to time-domain features, as we are interested in the identification of muscular activity rather than its classification and evaluation. From this perspective, the employment of further EMG features expressed in the frequency domain, e.g., mean frequency, median frequency or power spectral density [50], or mixed time-frequency domain, e.g., spectrogram or signal phase [51], assume a rather computationally complex extraction which is unjustified for our work.

The EMG feature values to discriminate walking from rest, as identified in our previous work reported in [44], are listed in Table 4. The EMG features for running and jumping are also listed for illustration. As indicated, there is some overlapping between the feature ranges. For example, a RMS value of 0.15 accounts for both walking and rest. This overlapping can be handled, provided all four features are assessed simultaneously. Indeed, the same RMS value of 0.15 in context with a MAV value of 0.15 and a $Z C$ value of 7 accounts for walking. For exemplification, the EMG features extracted for a walking segment are plotted in Figure 12.

Table 4. EMG feature range for the discrimination of walking from rest [44].

\begin{tabular}{ccccc}
\hline Title 1 & MAV & ZC & SSC & RMS \\
\hline Walking & $0.1-0.2$ & $5-10$ & $10-20$ & $0.1-0.3$ \\
Running & $0.2-0.4$ & $10-30$ & $10-20$ & $0.2-0.5$ \\
Jumping & $0.5-1$ & $10-20$ & $15-25$ & $0.3-0.6$ \\
Rest & $<0.1$ & $>15$ & $>25$ & $<0.2$ \\
\hline
\end{tabular}

\subsection{Correlation of the Plantar Pressure with Muscular Activity}

In this work, gait assessment is twofold. On one hand we performed the assessment of the plantar pressure along the COP progression line. On the other hand, we performed EMG assessment of the tibialis anterior and the gastrocnemius via the extracted features.

The target of this paper is to correlate the FSR readings with the lower-limb EMG in order to perform gait assessment. Indeed, physiological gait assumes a very clear correlation of the plantar pressures with the lower-limb muscles. As such, we are able to assess physiological gait based on FSR and EMG correlation for the heel strike and toe-off phases. The time-domain plots in Figure 13 illustrates the clear interdependency of the $\mathrm{FSR}_{5}$ and tibialis anterior EMG signals for heel strike, as well as the interdependency of the $\mathrm{FSR}_{0}$ and gastrocnemius EMG signals respectively for toe-off. 


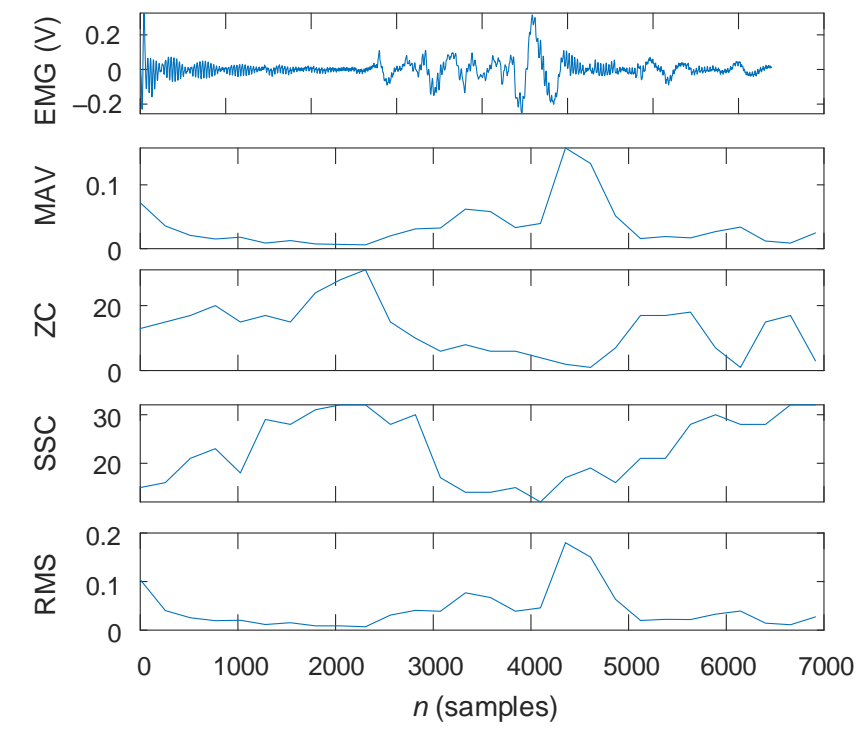

Figure 12. The lower-limb electromyogram (EMG) of a walking segment with the corresponding extracted features.

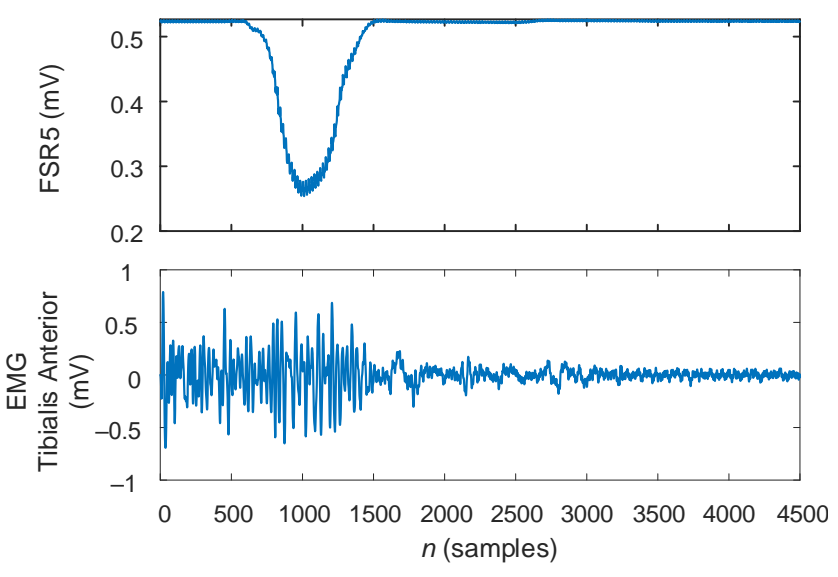

(a)

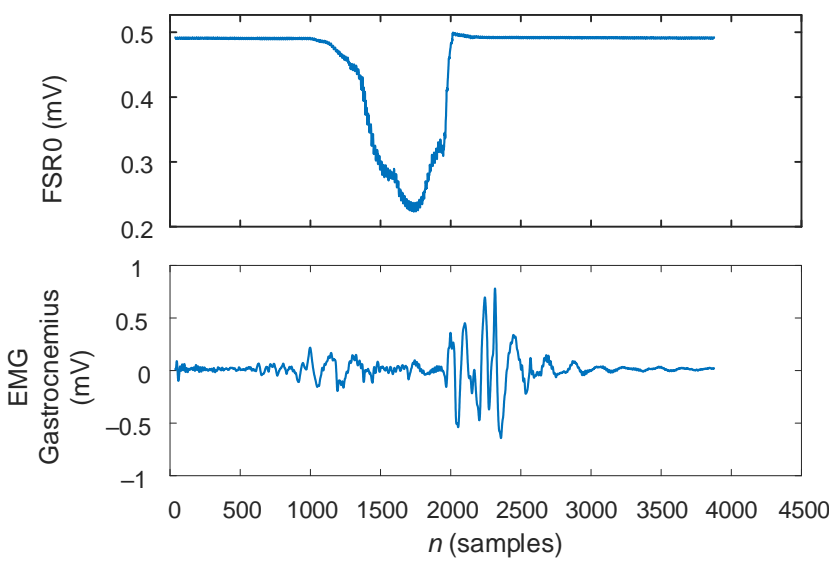

(b)

Figure 13. Time-domain plots of the force sensor resistors (FSR) and EMG signals illustrating a clear interdependency during the gait phases: (a) $\mathrm{FSR}_{5}$ and tibialis anterior at heel strike, (b) $\mathrm{FSR}_{0}$ and gastrocnemius at toe-off.

As illustrated in Figure 13a for heel strike, a direct dependency can be formulated between the plantar pressure executed on $\mathrm{FSR}_{5}$ and muscular activity of the tibialis anterior. Similarly, as illustrated in Figure 13b for toe-off, a direct dependency can be formulated between the plantar pressure executed on $\mathrm{FSR}_{0}$ and muscular activity of the gastrocnemius. However, it should be noticed that gastrocnemius activation and $\mathrm{FSR}_{0}$ activation exhibit a certain delay for toe-off, rather than simultaneity which is the case for $\mathrm{FSR}_{5}$ and tibialis anterior at heel strike. As such, this delay must be accounted for when correlating FSR with the EMG of the gastrocnemius.

The procedure followed to correlate FSR activation with muscular activity is performed as follows. Both FSR readings and the muscular activity have been binarized. The FSR signal was binarized by comparison to a threshold level, determined empirically in laboratory environment during extensive testing of the pressure sensors deployed onto the shoe insole. Muscular activity on the other hand was determined from the SSCindicating the onset of movement, and the MAV-indicating muscular intensity. The EMG features were binarized by comparison to a threshold level, determined for the MAV and 
SSC as follows. The MAV threshold value was considered 0.05 , that is half of the lower limit of the feature variation range in Table 4. The SSC threshold was considered 25, that is half of the lower limit of the feature variation range in Table 4 added to the upper limit. Additionally, considering that muscular activity is accounted for by low SSC values, SSC binarization is complementary, i.e., binarized SSC is logical 1 provided the SSC is lower than the threshold. Then, muscular activity was determined as the logical AND functional between the binarized EMG features. Finally, correlation of the FSR reading with the EMG is evaluated as the cross-correlation of the binarized FSR signal and muscular activity respectively, expressed as

$$
R_{F S R, E M G}(m)=\left\{\begin{array}{c}
\sum_{n=0}^{n-m+1} \operatorname{FSR}(n+m) \cdot E M G(n), m \geq 0 \\
R_{E M G, F S R}(-m), m<0
\end{array},\right.
$$

where $m$ is the cross-correlation function index [52].

Cross-correlation of the FSR to the lower-limb muscular activity accounts for a local maximum in the origin provided that the FSR and muscular activation are interdependent. For exemplification, cross-correlation of the binarized FSR readings with the EMG activation from Figure 13 is illustrated in Figure 14. Indeed, since the FSR readings and EMG activations exhibit simultaneity-with the physiological delay in-between FSR $_{0}$ and the gastrocnemius, their cross-correlation exhibits a maximum in the origin.
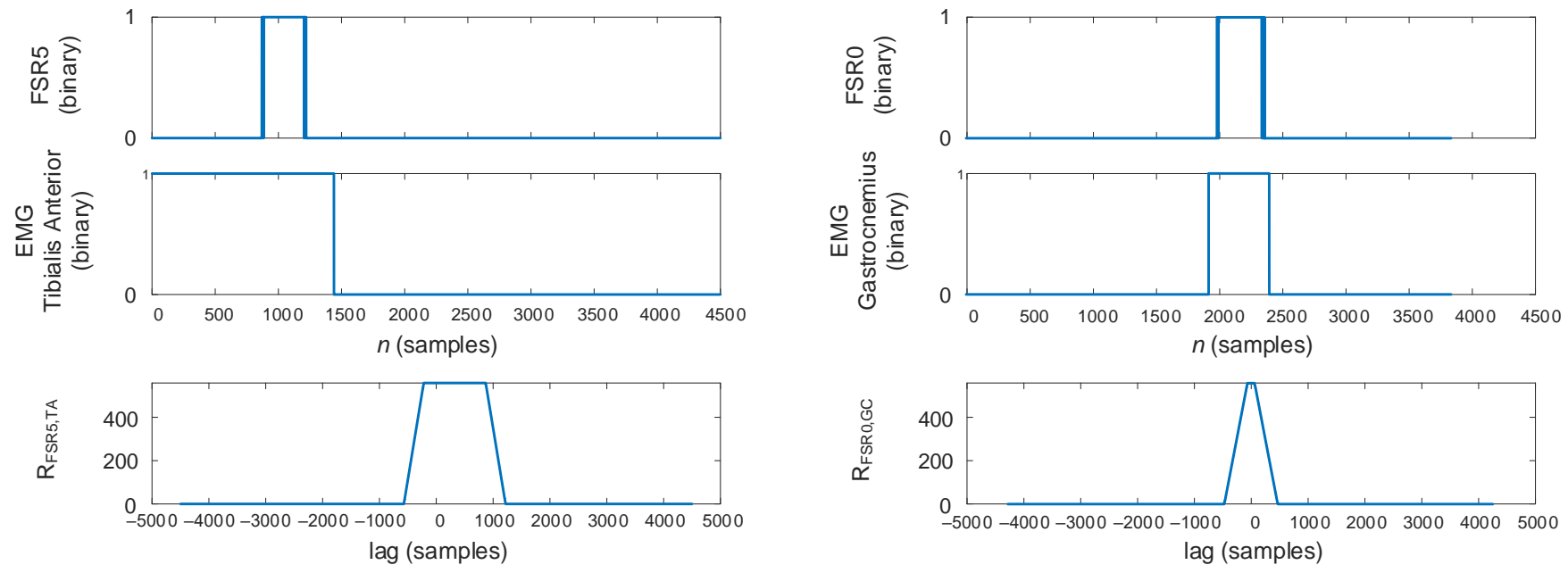

(a)

(b)

Figure 14. Illustration of the FSR and EMG interdependency via the cross-correlation of the binarized FSR reading and EMG activation which exhibits a maximum in the origin: (a) $\mathrm{FSR}_{5}$ and tibialis anterior at heel strike, and (b) FSR 0 and gastrocnemius at toe-off.

If on the other hand the FSR and the EMG activation are not interdependent, as illustrated in Figure 15a for FSR 1 and tibialis anterior and in Figure 15b for FSR 5 and gastrocnemius, their cross-correlation maxima will not be found in the origin, as illustrated in Figure 16. 

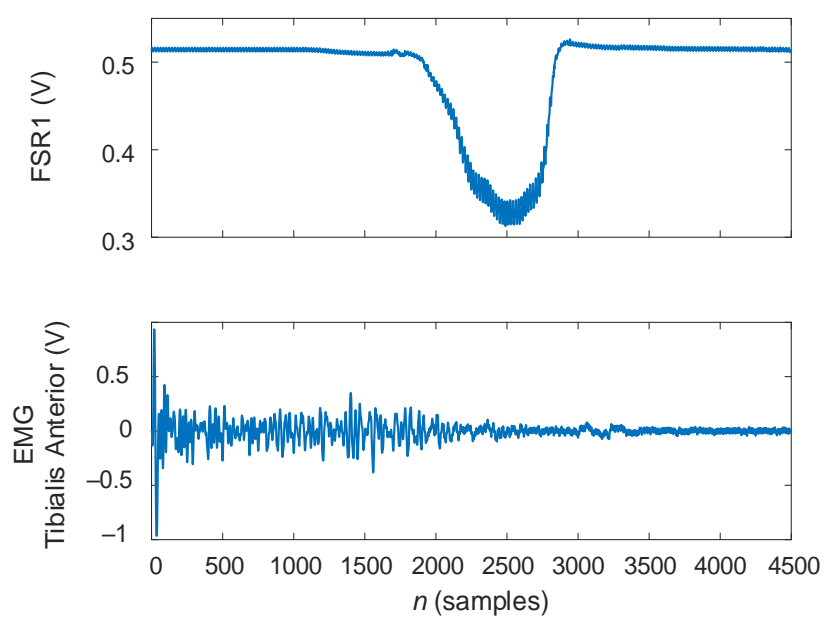

(a)
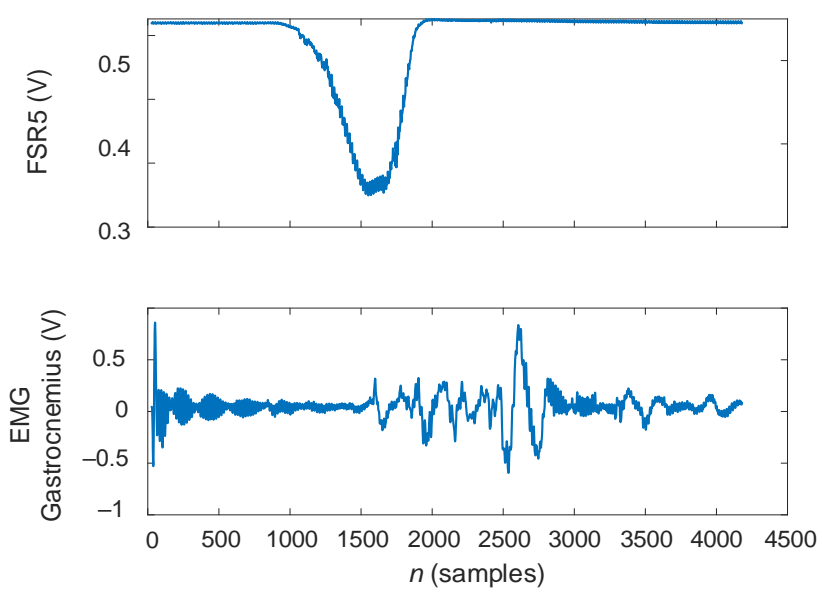

(b)

Figure 15. Time-domain plots of the FSR and EMG signals lack of interdependency during the gait phases: (a) FSR Fnd tibialis anterior at heel strike, (b) $\mathrm{FSR}_{5}$ and gastrocnemius at toe-off.
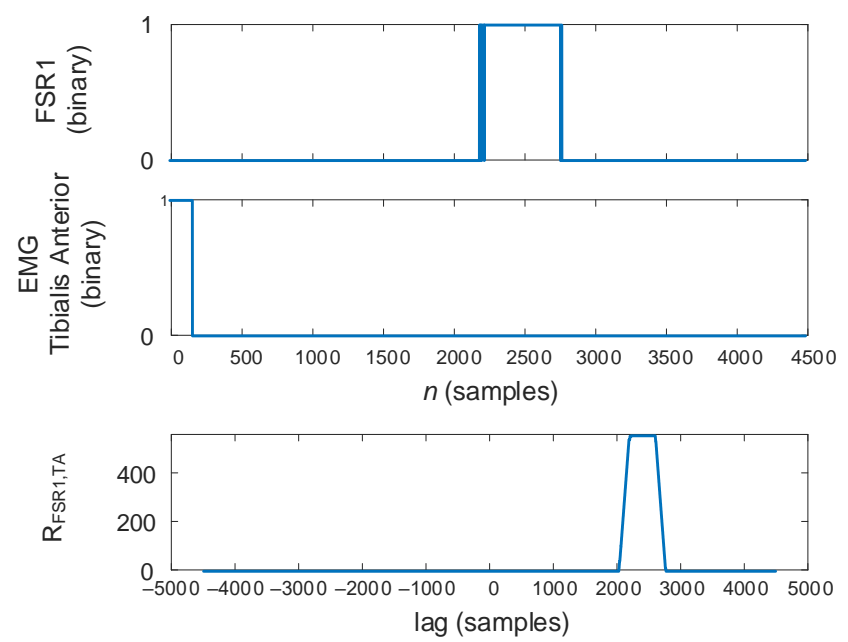

(a)
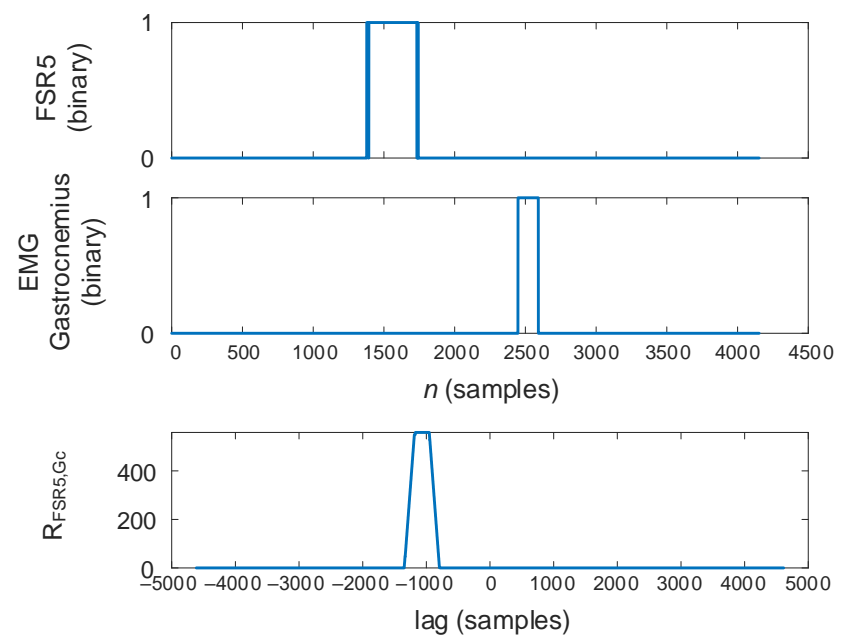

(b)

Figure 16. Illustration of the FSR and EMG lack of interdependency via the cross-correlation of the binarized FSR reading and EMG activation which does not have a maximum in the origin: (a) FSR 1 and tibialis anterior at heel strike, and (b) FSR and gastrocnemius at toe-off.

Another aspect which must pe pointed out at this stage is that, provided the crosscorrelation maxima of physiologically unrelated plantar pressures and muscular activities are still found in the origin, this is a clear indicator of non-physiological gait.

To be able to discriminate physiological from non-physiological gait respectively, we have further defined a gait map as the binary matrix representation of the interdependency between the FSRs and muscle activity. The matrix columns correspond to the gait phases as prescribed in Table 1. The matrix rows correspond to the cross-correlation of each FSR deployed onto the shoe insole with the tibialis anterior and the gastrocnemius respectively. Then, using Table 1, we were able to formulate the gait map template of the physiological gait cycle, namely which FSR is correlated to which muscle during the gait cycle. Accordingly, a logical ' 1 ' element in the gait map-stemming from the FSR-EMG cross-correlation maximum in the origin for the corresponding gait phase, accounts for the interdependency of the FSR with the muscular activity. A logical ' 0 ' on the other hand-stemming from the 
absence of a cross-correlation local maximum in the origin, states that the respective FSR and EMG are not interdependent.

The gait map template of physiological walking, according to the proposed definition, is illustrated in Table 5. Physiological gait is then decided based on the bi-dimensional cross-correlation of the gait map $G[12 \times 5]$ to the physiological gait map template $G_{\text {template }}$ $[1.2 \times 5]$, defined by:

$$
R_{\text {gaitmap }}(k, l)=\sum_{m=0}^{11} \sum_{n=0}^{4} G(m, n) G_{\text {template }}^{*}(m-k, n-l),
$$

where

$$
\begin{gathered}
k=[-11,11], \\
l=[-4,4]
\end{gathered}
$$

and (.)* denotes complex conjugation [52]. As such, it can be decided upon physiological gait provided the bi-dimensional cross-correlation function exhibits a maximum in the

\begin{tabular}{|c|c|c|c|c|c|}
\hline & \multicolumn{5}{|c|}{ Stance Phase } \\
\hline & $0-2 \%$ & $0-10 \%$ & $10-30 \%$ & $30-50 \%$ & $50-60 \%$ \\
\hline $\mathrm{R}_{\mathrm{FSR} 5, \mathrm{TA}}$ & 1 & 1 & 0 & 0 & 0 \\
\hline $\mathrm{R}_{\mathrm{FSR} 4 \mathrm{TA}}$ & 0 & 1 & 0 & 0 & 0 \\
\hline $\mathrm{R}_{\mathrm{FSR} 3, \mathrm{TA}}$ & 0 & 1 & 0 & 0 & 0 \\
\hline $\mathrm{R}_{\mathrm{FSR} 2, \mathrm{TA}}$ & 0 & 0 & 0 & 0 & 0 \\
\hline $\mathrm{R}_{\mathrm{FSR} 1, \mathrm{TA}}$ & 0 & 0 & 0 & 0 & 0 \\
\hline $\mathrm{R}_{\mathrm{FSR} 0, \mathrm{TA}}$ & 0 & 0 & 0 & 0 & 0 \\
\hline $\mathrm{R}_{\mathrm{FSR} 5, \mathrm{GC}}$ & 0 & 0 & 0 & 0 & 0 \\
\hline $\mathrm{R}_{\mathrm{FSR} 4, \mathrm{GC}}$ & 0 & 0 & 1 & 0 & 0 \\
\hline $\mathrm{R}_{\mathrm{FSR} 3, \mathrm{GC}}$ & 0 & 0 & 1 & 0 & 0 \\
\hline $\mathrm{R}_{\mathrm{FSR} 2, \mathrm{GC}}$ & 0 & 0 & 1 & 1 & 0 \\
\hline $\mathrm{R}_{\mathrm{FSR} 1, \mathrm{GC}}$ & 0 & 0 & 1 & 1 & 1 \\
\hline $\mathrm{R}_{\mathrm{FSR} 0, \mathrm{GC}}$ & 0 & 0 & 0 & 1 & 1 \\
\hline
\end{tabular}
origin.

Table 5. Template for the gait map of physiological walking.

\section{Results}

The laboratory proof of concept of the proposed wearable gait monitoring system was tested and validated indoors in laboratory environment. One healthy male volunteer, with no history of walking disorders, has tested the system under three walking scenarios: normal walking - accounting for physiological gait, and heel walking and toe walkingaccounting for pathological gait.

The walking activity assumed 20 steps of walking around the laboratory (as allowed by a $5 \mathrm{~m}$ long USB cable which connects the proposed wearable gait monitoring system to a laptop computer) with a pace of $13 \mathrm{~min} / \mathrm{km}$ (the pace was monitored with a personal Garmin Fenix 5 smartwatch). The left leg was considered to be the leading limb. The subject performed 5 trials of steady-state walking exercises to understand the required activity and one trial steady-state walking for subsequent analysis with the proposed gait monitoring system.

We have considered the onset of gait as the first strike of the left leg after a minimum $10 \mathrm{~s}$ standstill. The first four steps, i.e., first two walking cycles, are accounted for gait initiation as prescribed by Park et al. in [53]. As such, gait analysis is performed subsequent to the first four steps.

The matter of the exact gait initiation moment must be clarified at this stage. According to Park et al., the onset of gait is defined as having less than $0.5 \%$ of half of the body weight on the leading limb in upright standstill posture [53]. With the proposed wearable gait monitoring system, we only monitor plantar pressures-without conversion to ground 
reaction forces or body weight, and also, we do not acquire any information regarding joint motion and posture. As such, we are unable to assess gait initiation as prescribed by Park et al. Nevertheless, the accent in this work is on analyzing steady state walking, and as such, gait onset and gait initiation do not render useful information. Moreover, the exact moment of gait onset will not alter whatsoever on the assessment of steady state walking. A set of conclusive test results is presented as follows.

The FSR recordings during a stance phase are plotted in Figure 17. The corresponding COP progression line, rendered with Processing, is illustrated in Figure 18. As shown both in Figures 17 and 18, normal gait follows the evolution of the plantar pressures starting with pressure recorded on $\mathrm{FSR}_{5}$ at heel strike, followed by pressure along the footprint medial line $\mathrm{FSR}_{4}$ towards $\mathrm{FSR}_{1}$, and finally pressure on $\mathrm{FSR}_{0}$ at toe-off. Deviations from the COP progression line are an indicator of some form of gait pathology.
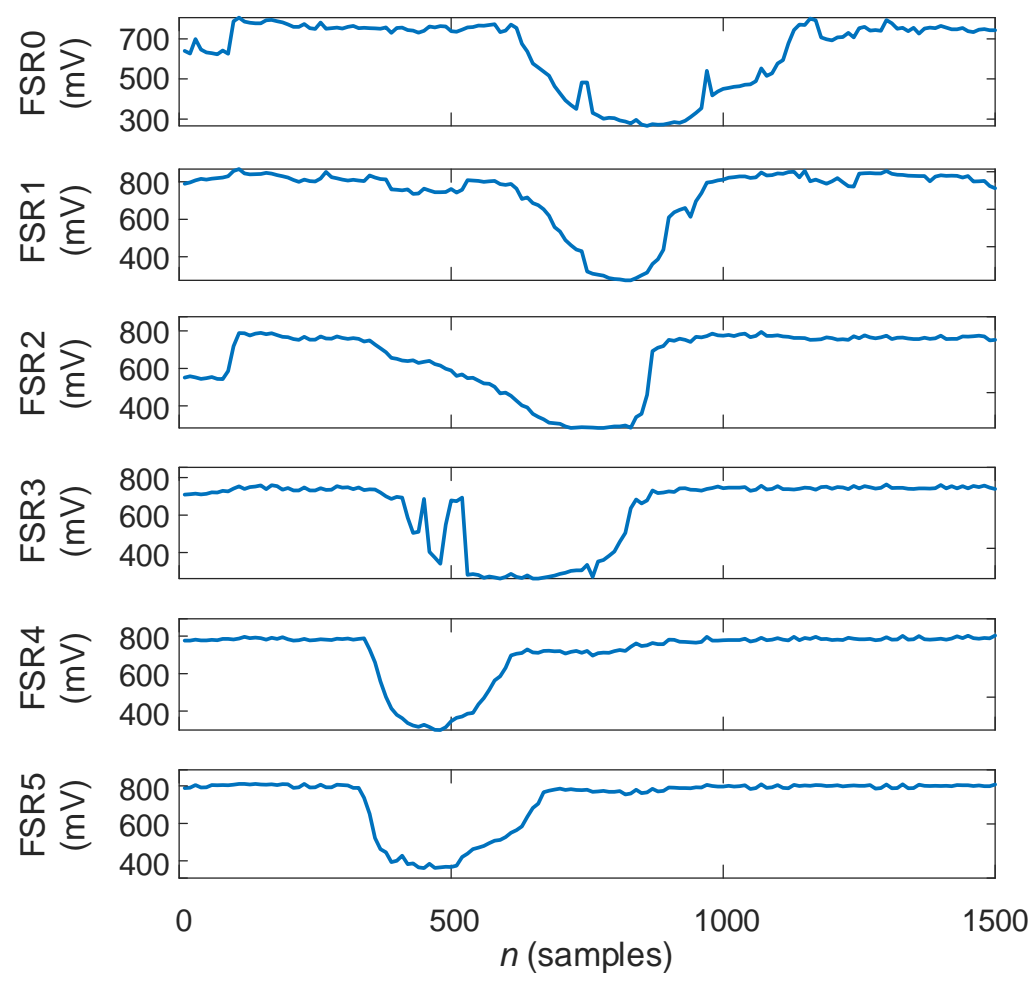

Figure 17. The FSR recordings during a stance phase, following the successive activation of $\mathrm{FSR}_{5}-$ heel area, $\mathrm{FSR}_{4}$ to $\mathrm{FSR}_{1}$ — midfoot, and $\mathrm{FSR}_{0}$ - hallux.

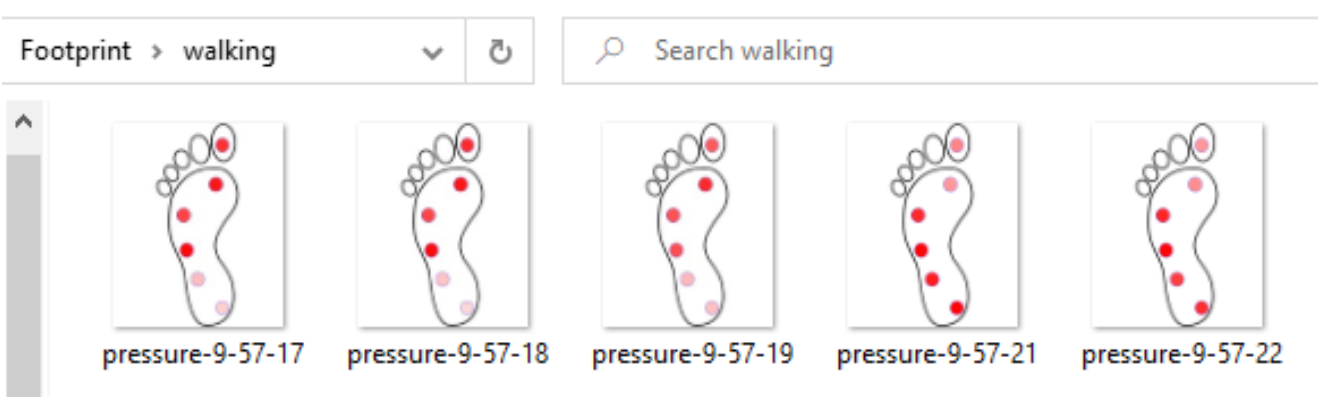

Figure 18. The COP progression line during a stance phase with light red indicating applied pressure, following the successive activation of FSR 5 -heel area, $\mathrm{FSR}_{4}$ to $\mathrm{FSR}_{1}$-midfoot, and $\mathrm{FSR}_{0}$ — hallux.

Further on, the FSR readings are plotted in Figure 19 alongside the EMG of the tibialis anterior and gastrocnemius respectively. As illustrated, plantar pressures and muscular 
activity are indeed interdependent during the physiological gait cycle as prescribed in Table 1.
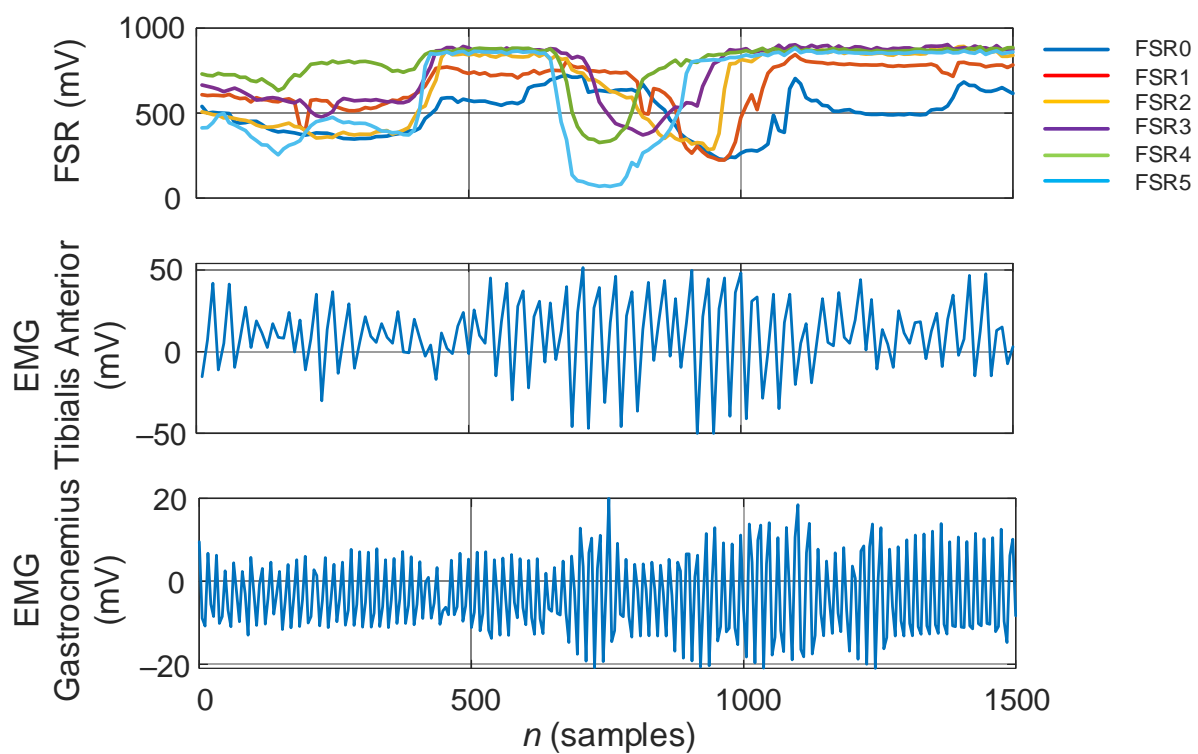

Figure 19. The FSR recordings during a stance phase, plotted alongside the tibialis anterior and gastrocnemius EMG respectively.

Assessment of the interdependency between plantar pressure and muscular activity requires a more thorough analysis performed via cross-correlation, as described in mboxsectsect:sec2dot3-applsci-1038217. The actual muscular activation pattern, determined for both tibialis anterior and gastrocnemius on the basis of the EMG features, is illustrated in Figure 20.

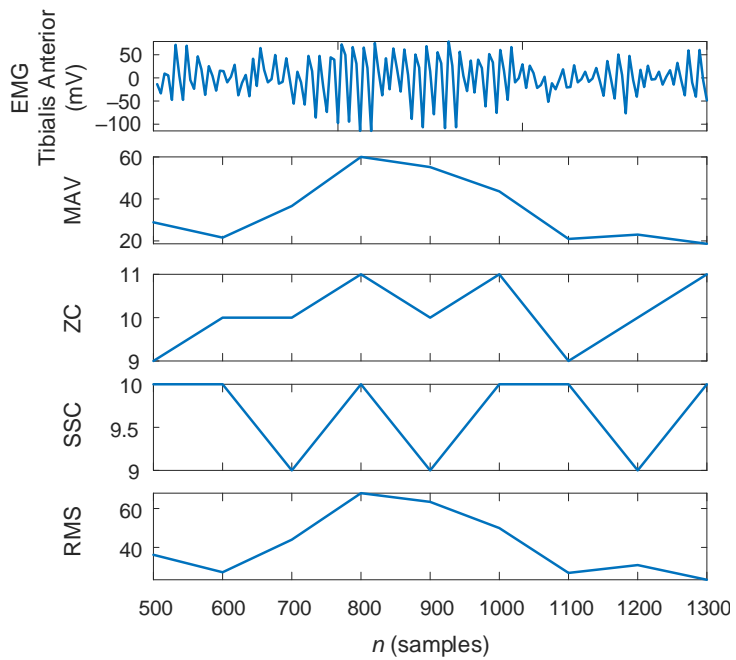

(a)

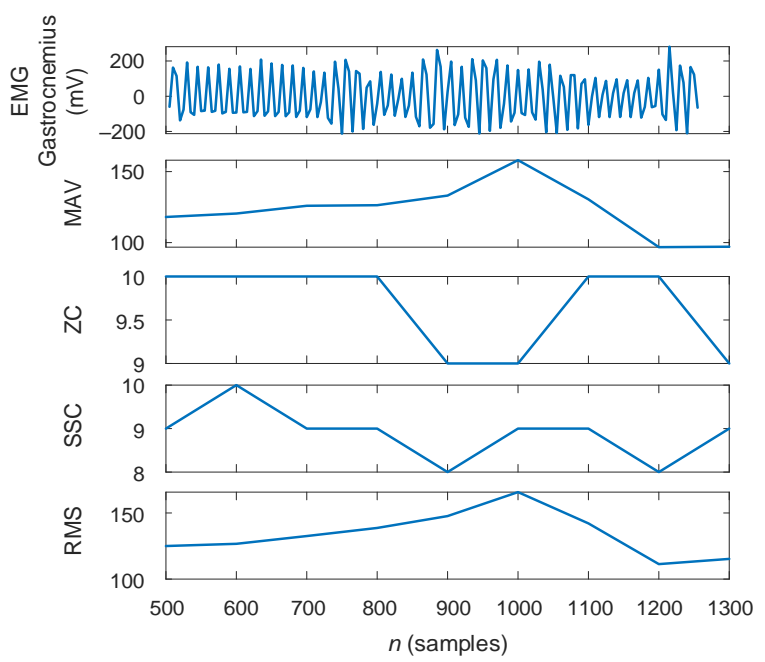

(b)

Figure 20. Muscular activation pattern determined based on the EMG extracted feature for (a) tibialis anterior and (b) gastrocnemius.

The values of the EMG feature magnitudes, as read from Figure 20, discriminate walking form resting as prescribed by Table 4 (a 100× multiplier was considered for MAV and RMS). This enables the evaluation of the FSR and EMG cross-correlation in the context of walking, aiming towards the decision upon physiological gait. 
The FSR was correlated with the EMG muscular activity as prescribed by Equation (6). The cross-correlation results of the FSR and EMG signals are plotted in Figure 21 for the tibialis anterior and the gastrocnemius respectively. As illustrated, the tibialis anterior cross-correlation maximum is in the origin with $\mathrm{FSR}_{5}$, indicating that the tibialis anterior is activated for heel strike during physiological gait. Similarly, the gastrocnemius crosscorrelation maximum is in the origin with $\mathrm{FSR}_{0}$, indicating that gastrocnemius is activated for toe-off during physiological gait. On the other hand, cross-correlation maxima outside the origin indicates that muscular activity occurred before/after FSR activation., e.g., pressure is read on $\mathrm{FSR}_{0}$ only after activity on the tibialis anterior-motivating the shift of the $\mathrm{R}_{\mathrm{FSR} 0, \mathrm{TA}}$ maximum from the origin, whereas FSR5 reads pressure before gastrocnemius activity - motivating the shift of the $\mathrm{R}_{\mathrm{FSR} 5, \mathrm{GC}}$ from the origin.

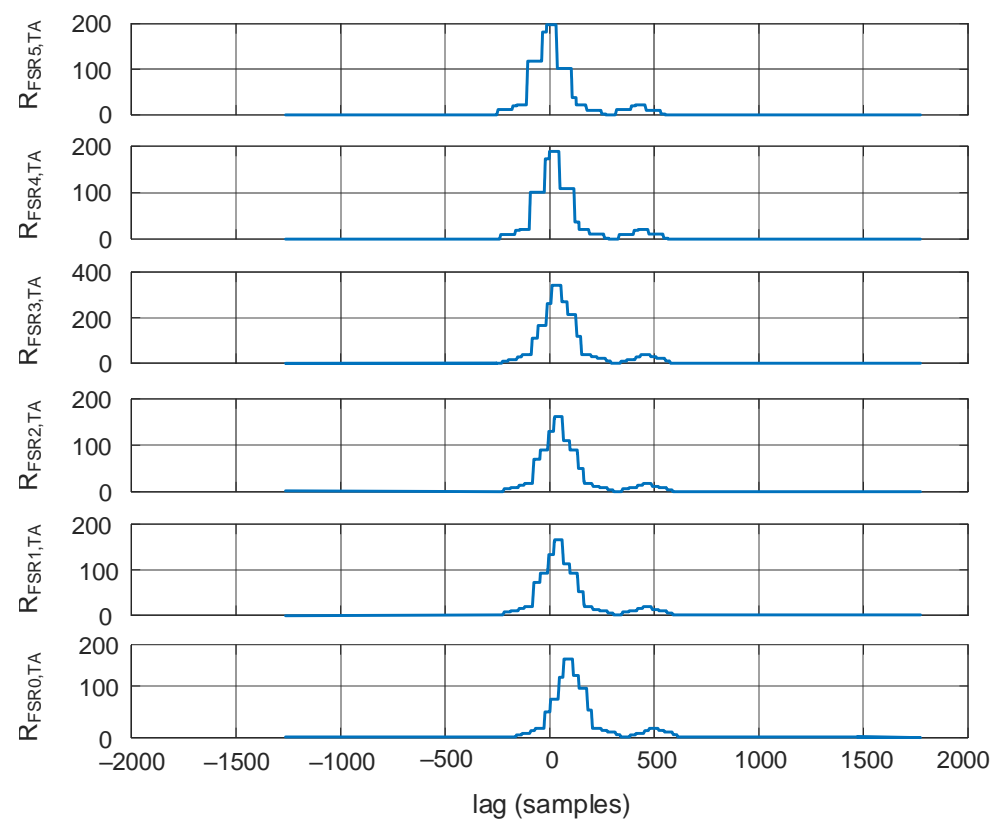

(a)
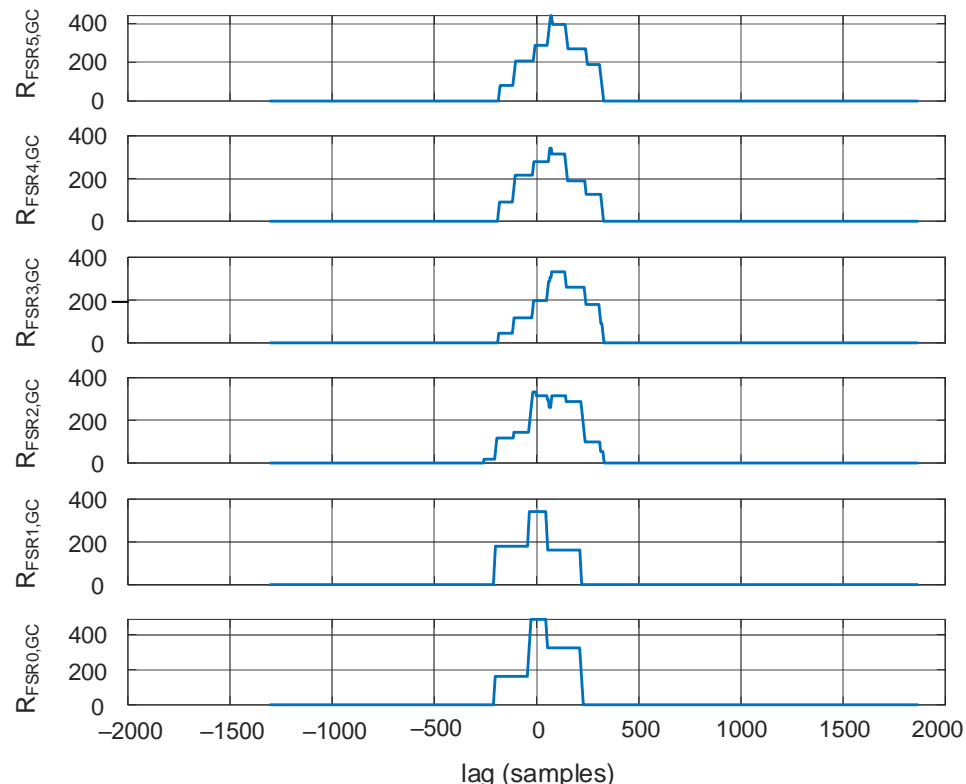

(b)

Figure 21. Cross-correlation of the FSRs to the (a) tibialis anterior and the (b) gastrocnemius. 
The cross-correlation results plotted in Figure 21 enable the formulation of the gait map listed in Table 6. Indeed, the cross-correlations plotted in Figure 21 illustrate the interdependency of the investigated plantar pressure point with muscular activity during gait. On the cross-correlation plots, we have identified the lags corresponding to the middle of each gait cycle. Then, we have compared the cross-correlation function magnitude to a threshold level equal to 0.75 of the cross-correlation maxima, having the 0.75 fraction determined empirically. Cross-correlation magnitudes larger than the threshold account correlation of the plantar pressure with the muscle in the respective gait cycle, i.e., logical ' 1 ' in the gait map, whereas cross-correlation magnitudes below the threshold level account for lack o correlation, i.e., logical ' 0 ' in the gait map. The gait map formulation process, according to the explanation beforehand, is depicted in Figure 22.

Table 6. The gait map for the stance phase plotted in Figure 19, generated from the cross-correlation functions from Figure 21.

\begin{tabular}{|c|c|c|c|c|c|}
\hline & \multicolumn{5}{|c|}{ Stance Phase } \\
\hline & $0-2 \%$ & $0-10 \%$ & $10-30 \%$ & $30-50 \%$ & $50-60 \%$ \\
\hline $\mathrm{R}_{\mathrm{FSR} 5, \mathrm{TA}}$ & 1 & 1 & 0 & 0 & 0 \\
\hline $\mathrm{R}_{\mathrm{FSR} 4, \mathrm{TA}}$ & 1 & 1 & 0 & 0 & 0 \\
\hline $\mathrm{R}_{\mathrm{FSR} 3, \mathrm{TA}}$ & 0 & 1 & 1 & 0 & 0 \\
\hline $\mathrm{R}_{\mathrm{FSR} 2, \mathrm{TA}}$ & 0 & 1 & 1 & 0 & 0 \\
\hline $\mathrm{R}_{\mathrm{FSR} 1, \mathrm{TA}}$ & 0 & 1 & 1 & 1 & 0 \\
\hline $\mathrm{R}_{\mathrm{FSR} 0, \mathrm{TA}}$ & 0 & 0 & 1 & 1 & 0 \\
\hline $\mathrm{R}_{\mathrm{FSR} 5, \mathrm{GC}}$ & 0 & 0 & 1 & 0 & 0 \\
\hline $\mathrm{R}_{\mathrm{FSR} 4, \mathrm{GC}}$ & 0 & 0 & 1 & 0 & 0 \\
\hline $\mathrm{R}_{\mathrm{FSR} 3, \mathrm{GC}}$ & 0 & 0 & 1 & 0 & 0 \\
\hline $\mathrm{R}_{\mathrm{FSR} 2, \mathrm{GC}}$ & 0 & 1 & 1 & 1 & 1 \\
\hline $\mathrm{R}_{\mathrm{FSR} 1, \mathrm{GC}}$ & 0 & 0 & 0 & 1 & 1 \\
\hline $\mathrm{R}_{\mathrm{FSR} 0, \mathrm{GC}}$ & 0 & 0 & 0 & 1 & 1 \\
\hline
\end{tabular}

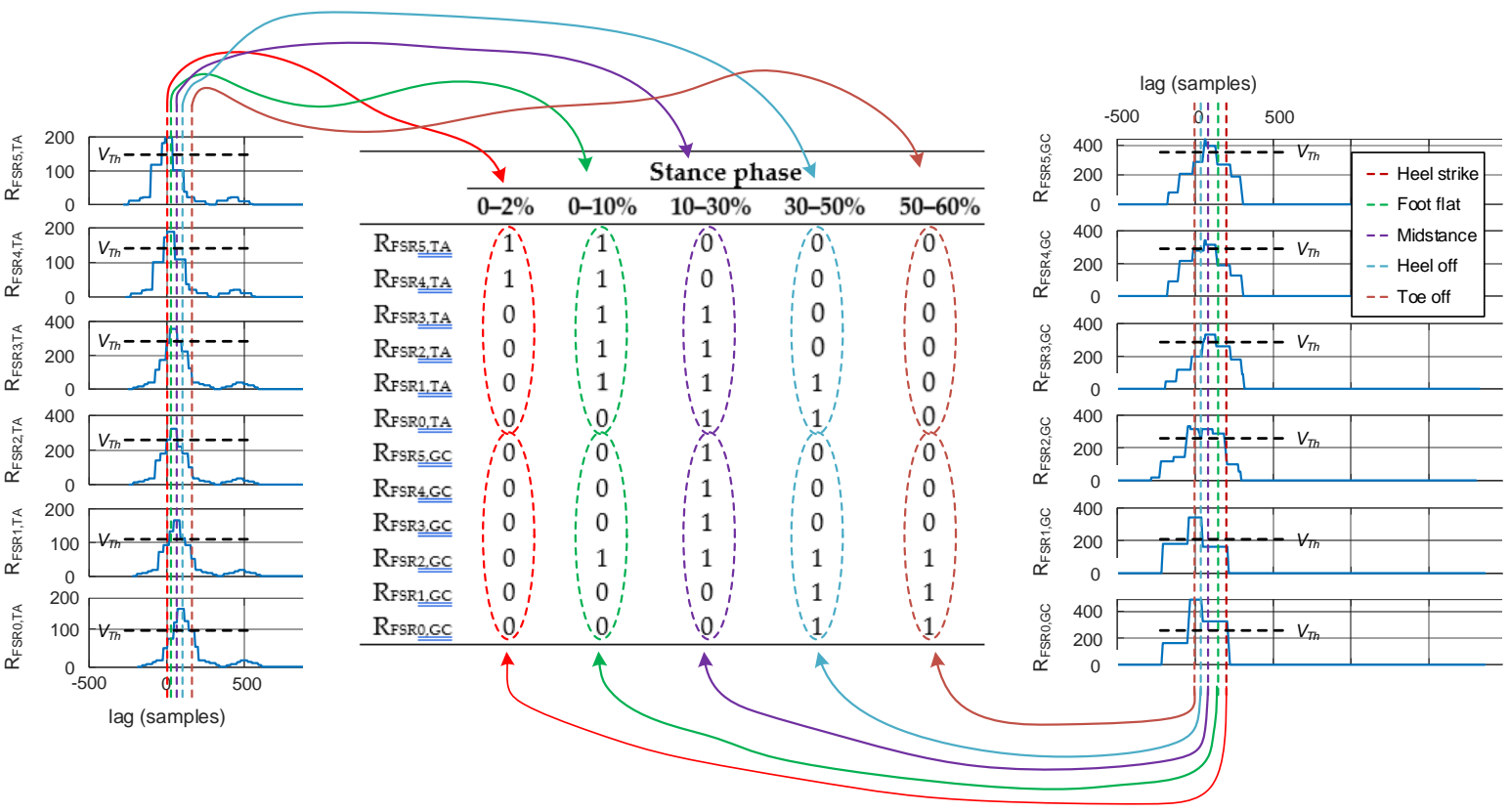

Figure 22. The FSR recordings during a stance phase, plotted alongside the tibialis anterior and gastrocnemius EMG respectively. 
The results of its bi-dimensional cross-correlation to the physiological gait map template from Table 5 results in the surface plot from Figure 23. The maximum in the crosscorrelation origin accounts for the identification of physiological gait.

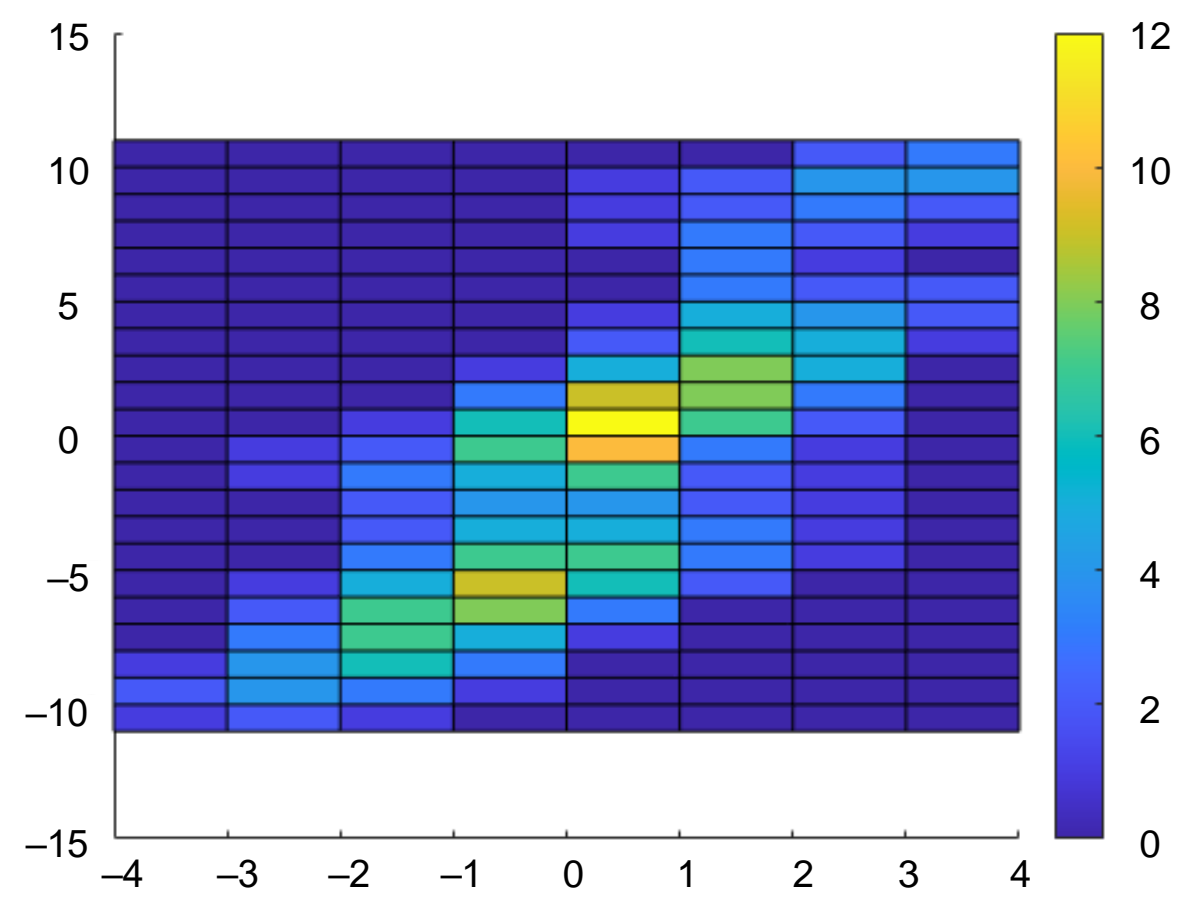

Figure 23. Surface plot of the bi-dimensional cross-correlation of the gait map from Table 5 to the physiological gait map template from Table 4.

Regarding the discrimination of pathological gait, Table 7a illustrates the gait map of heel-walking, whereas Table $7 \mathrm{~b}$ illustrates the gait map of a toe-walking. The crosscorrelation results of each gait map to the reference gait map from Table 4 are plotted in Figure 24. It should be noticed both defective walking patterns were reproduced by the healthy volunteer for illustration purpose. Both are described as follows.

Table 7. The gait map for the stance phase for (a) heel walking, and (b) toe walking.

(a)

\begin{tabular}{|c|c|c|c|c|c|}
\hline & \multicolumn{5}{|c|}{ Stance Phase } \\
\hline & $0-2 \%$ & $0-10 \%$ & $10-30 \%$ & $30-50 \%$ & $50-60 \%$ \\
\hline $\mathrm{R}_{\mathrm{FSR} 5, \mathrm{TA}}$ & 1 & 1 & 1 & 1 & 1 \\
\hline $\mathrm{R}_{\mathrm{FSR} 4, \mathrm{TA}}$ & 0 & 0 & 1 & 1 & 0 \\
\hline $\mathrm{R}_{\mathrm{FSR} 3, \mathrm{TA}}$ & 0 & 0 & 0 & 0 & 0 \\
\hline $\mathrm{R}_{\mathrm{FSR} 2, \mathrm{TA}}$ & 0 & 0 & 0 & 0 & 0 \\
\hline $\mathrm{R}_{\mathrm{FSR} 1, \mathrm{TA}}$ & 0 & 0 & 0 & 0 & 0 \\
\hline $\mathrm{R}_{\mathrm{FSR} 0, \mathrm{TA}}$ & 0 & 0 & 0 & 0 & 0 \\
\hline $\mathrm{R}_{\mathrm{FSR} 5, \mathrm{GC}}$ & 0 & 0 & 1 & 1 & 1 \\
\hline $\mathrm{R}_{\mathrm{FSR} 4, \mathrm{GC}}$ & 0 & 0 & 1 & 1 & 0 \\
\hline $\mathrm{R}_{\mathrm{FSR} 3, \mathrm{GC}}$ & 0 & 0 & 0 & 0 & 0 \\
\hline $\mathrm{R}_{\mathrm{FSR} 2, \mathrm{GC}}$ & 0 & 0 & 0 & 0 & 0 \\
\hline $\mathrm{R}_{\mathrm{FSR} 1, \mathrm{GC}}$ & 0 & 0 & 0 & 0 & 0 \\
\hline $\mathrm{R}_{\mathrm{FSR} 0, \mathrm{GC}}$ & 0 & 0 & 0 & 0 & 0 \\
\hline
\end{tabular}


Table 7. Cont.

\begin{tabular}{|c|c|c|c|c|c|}
\hline & \multicolumn{5}{|c|}{ (b) } \\
\hline & \multicolumn{5}{|c|}{ Stance Phase } \\
\hline & $0-2 \%$ & $0-10 \%$ & $10-30 \%$ & $30-50 \%$ & $50-60 \%$ \\
\hline $\mathrm{R}_{\mathrm{FSR} 5, \mathrm{TA}}$ & 0 & 0 & 0 & 0 & 0 \\
\hline $\mathrm{R}_{\mathrm{FSR} 4, \mathrm{TA}}$ & 0 & 0 & 0 & 0 & 0 \\
\hline $\mathrm{R}_{\mathrm{FSR} 3, \mathrm{TA}}$ & 0 & 0 & 0 & 0 & 0 \\
\hline $\mathrm{R}_{\mathrm{FSR} 2, \mathrm{TA}}$ & 0 & 0 & 0 & 1 & 0 \\
\hline $\mathrm{R}_{\mathrm{FSR} 1, \mathrm{TA}}$ & 0 & 0 & 0 & 1 & 1 \\
\hline $\mathrm{R}_{\mathrm{FSR} 0, \mathrm{TA}}$ & 0 & 0 & 0 & 1 & 1 \\
\hline $\mathrm{R}_{\mathrm{FSR} 5, \mathrm{GC}}$ & 0 & 0 & 0 & 0 & 0 \\
\hline $\mathrm{R}_{\mathrm{FSR} 4, \mathrm{GC}}$ & 0 & 0 & 0 & 0 & 0 \\
\hline $\mathrm{R}_{\mathrm{FSR} 3, \mathrm{GC}}$ & 0 & 0 & 0 & 0 & 0 \\
\hline $\mathrm{R}_{\mathrm{FSR} 2, \mathrm{GC}}$ & 0 & 1 & 1 & 0 & 0 \\
\hline $\mathrm{R}_{\mathrm{FSR} 1, \mathrm{GC}}$ & 1 & 1 & 1 & 1 & 1 \\
\hline $\mathrm{R}_{\mathrm{FSR} 0, \mathrm{GC}}$ & 1 & 1 & 1 & 1 & 1 \\
\hline
\end{tabular}

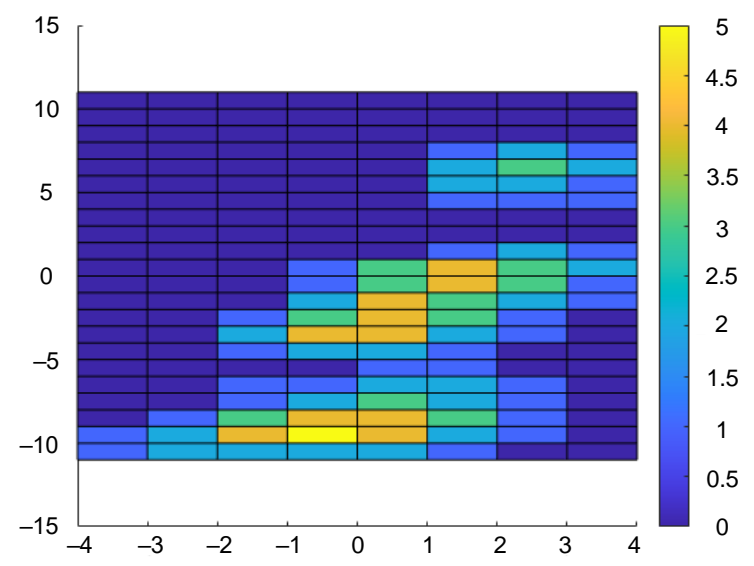

(a)

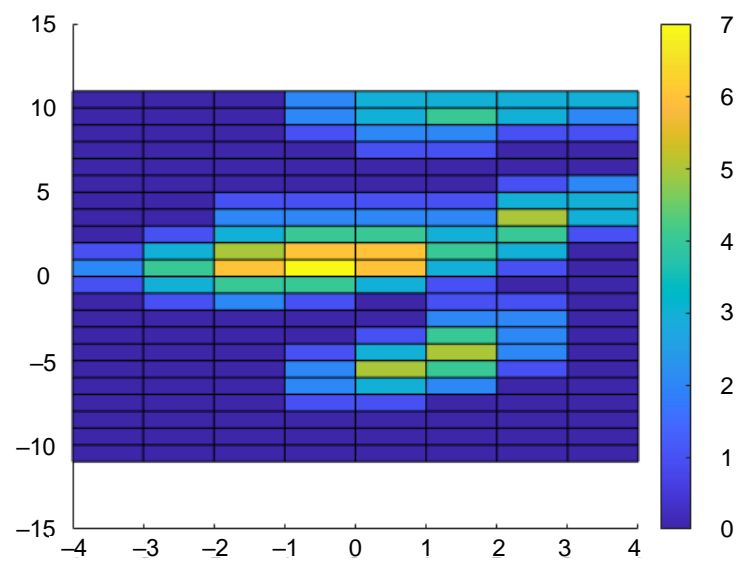

(b)

Figure 24. Surface plot of the bi-dimensional cross-correlation of the gait map from Table 7 to the physiological gait map template from Table 4 for (a) heel walking, and (b) toe walking.

Table 7a reads that heel-walking accounts for plantar pressure on the heel area, i.e., FSR along the complete stance phase, and on the lateral heel/heel section of the metatarsal arch, i.e., $\mathrm{FSR}_{4}$, during midstance. The tibialis anterior activity is recorded along the complete stance phase, according for foot dorsiflexion during heel walking. The gastrocnemius on the other hand is activated only during lifting of the foot. The fact that this walking pattern does not account for physiological gait is visible in the surface plot from Figure 24a-illustrating the cross-correlation result of the heel-walking gait map to the reference gait map from Table 4, which exhibits the maximum outside the origin.

Table $7 \mathrm{~b}$ reads that toe-walking accounts for pressure readings on the toe and metatarsal arches respectively, i.e., $\mathrm{FSR}_{0}, \mathrm{FSR}_{1}$ and $\mathrm{FSR}_{2}$ respectively, during strike, with the corresponding activation of the gastrocnemius, followed by the activation of the tibialis anterior at toe off. Gastrocnemius activity along the whole stance phase accounts for plantar flection along toe-walking. The corresponding surface plot from Figure $24 \mathrm{~b}$, illustrating the cross-correlation results of the toe-walking gait map to the reference gait map from Table 4, exhibits its maximum outside the origin, highlighting the fact that toe-walking does not account for physiological walking. 


\section{Discussion}

Standing of humans is performed using sensory information from the ankle muscles, provided mainly by the gastrocnemius, soleus and tibialis anterior. While standing, muscle activation depends on the position of the COP. For balance, when the body sways forward and the COP moves forward, the gastrocnemius and the soleus are activated. When the body sways backwards and the COP moves backwards, the tibialis anterior is activated. In muscle activation, autogenic reflexes for postural control are particularly important [54].

Gait is an even more complicated process in comparison to standing. It needs the neuromuscular systems to control the body along with a healthy and functional skeletal system. A good muscle ankle control is essential both for maintaining stance and for gait.

In this context, the proposed foot biomechanics wearable monitoring system provides a viable solution for the assessment of both plantar pressure distribution along the COP progression line and lower-limb muscular activity via two EMG channels.

Through EMG recordings, our study sustains that ankle movement in the sagittal plane during the stance phase is controlled by the interaction between agonist and antagonist muscles of the leading limb. Both relaxation of the gastrocnemius and contraction of the tibialis anterior, which dorsiflexes the ankle, make the heel strike possible by the fact that the COP is brought posterior to the ankle. For the remainder of the stance phases, the two muscles work in opposite phases, enabling the advancement of the COP through the forward rolling of the foot. Visualization of this phenomenon is enabled by the proposed distribution of the pressure sensors on the shoe insole.

During the forward rolling of the foot, which implies ankle plantar flexion, the COP progresses anteriorly from the heel, yet not in a straight line due to the frontal plane movements of the foot, i.e., supination and pronation. During the stance phase, the last point of pressure is the toe, when the swing phase follows toe-off. Tibialis anterior contributes to the dorsiflexion of the foot in the pronation of the foot.

A novelty of the work proposed in this paper is the underlaying software application which performs the cross-correlation of the plantar pressures, specifically the progression of the COP, with the lower-limb muscular activity. The cross-correlation results in a matrix representation of the gait pattern, i.e., the proposed gait map. Objective gait evaluation is then performed by comparing the gait map to a reference map of the physiological gait. As such, our study reveals a healthy muscle activity pattern for the investigated ankle and 'foot.

Our tests were carried out under the assumption of healthy lower-limb muscles. As such, the AFE gain was set to amplify the nominal $1 \mu \mathrm{V}-10 \mathrm{mV}$ EMG amplitude range into the $+/-\mathrm{mV}$ amplitude rage prior to ADC. At this stage, a discussion worth having regards the variation of the EMG amplitude as a result of muscular disease and its effects on gait assessment using the proposed system. Under this gain configuration however, small EMG amplitudes will not be sensed by the AFEs employed in the proposed system, whereas large EMG signals will determine features outside the ranges listed in Table 4, leading to erroneous identification of walking. To counter such effects, gain adaptation techniques, e.g., [55], can be envisioned for the proposed system.

Another discussion regards the effects of noise and EMG artifacts on the operation of the proposed system. A noise-free EMG signal, containing only information regarding muscular activity, accounts for the ideal operating conditions for system operation. The presence of artifacts however may determine features outside the ranges listed in Table 4, thus leading to erroneous identification of walking. Considering the targeted bandwidth, i.e., $150 \mathrm{~Hz}$ which accounts for both muscular activity and the activation pattern of the investigated muscles, high-frequency motion artifacts and stray interference are attenuated inherent to system operation. Low-frequency long-term baseline artifacts will be suppressed by DC and low-frequency rejection. Low-frequency short-term baseline artifacts on the other hand, as well as contact noise, will determine instantaneous alterations of the extracted feature amplitudes. Nevertheless, considering their relatively short duration, they can be identified and ignored for one gait cycle. 
The proposed solution for the gait monitoring system is also envisioned for employment in the identification of some pathologies. This aspect was illustrated and validated with tests reproducing pathological walking and is discussed further on.

When the ankles are disabled because diseases or weak extrinsic foot muscles, the movements of the foot are larger and the foot overpronates. The COP travels inwards and the ankle movers, mainly the tibialis anterior, will be overactive to compensate the deficiencies mentioned above. Muscle fatigue sets in early and can be identified through EMG.

If in standing posture the ankle has a $90^{\circ}$ position, the foot is in a neutral positionneither pronated nor supinated, and the foot muscles work coordinated, we expect that the proposed monitoring system will record a normal COP progression line. If however the standing posture faces pronated or supinated foot, imbalances in extrinsic foot muscles, or even unhealthy shoes, one will visualize deviations or even absence of pressures throughout the footprint areas that are monitored.

Alterations in the frontal plane mechanics of the foot can as well be assessed with the proposed monitoring system. Findings may indicate either towards faulty foot postureassessed with the pressure sensors deployed onto the shoe insole, or to shank muscle imbalances-highlighted by EMG.

As mentioned earlier, based on kinetic link principle, the human body must be considered in terms of a series of interrelated links or segments [28]. Alterations in the frontal plane mechanics of the foot have been linked to foot and ankle injuries, knee pathology, alterations in the hip muscle recruitment strategies, and may be associated with lumbosacral dysfunction [56]. Spine faulty posture and lumbosacral dysfunction may be associated with foot faulty posture as well as ankle and foot dysfunction. Considering that the ankle and foot musculoskeletal complex is implied in the ankle joint strategy-a strategic element of balance control with implications in stance and gait, the functional evaluation of the foot is essential. Our system contributes to functional evaluation of the lower limb, ankle and foot, during a functional movement, the gait. Along with disease prevention, limitations is important for rehabilitation purposes as well. Further on, it might be useful for body functional movements training and to control the correction of the foot by orthotic insoles.

This paper presented a laboratory proof of concept for a wearable gait monitoring system, with the novelty consisting in the underlying software application which correlates plantar pressures with lower-limb EMG and performs gait analysis based on a gait map. Tests performed in the laboratory environment validate the proposed solution for the discrimination of physiological from pathological walking. As such, the next steps aim toward miniaturization and the integration of the proposed system concept into a wearable and portable device, and to undergo cohort studies in clinical environment.

Author Contributions: Conceptualization, P.F. and M.-A.F.; methodology, P.F., L.G. and S.H.; software, P.F.; validation, L.G. and S.H.; investigation, P.F. and M.-A.F.; resources, M.-A.F.; writingoriginal draft preparation, P.F., L.G. and M.-A.F.; writing-review and editing, S.H.; visualization, S.H.; supervision, S.H.; project administration, S.H. All authors have read and agreed to the published version of the manuscript.

Funding: This research received no external funding.

Institutional Review Board Statement: Not applicable.

Informed Consent Statement: Not applicable.

Data Availability Statement: Data sharing not applicable.

Acknowledgments: This research was supported by the project 21 PFE in the frame of the programme PDI-PFE-CDI 2018.

Conflicts of Interest: The authors declare no conflict of interest. 


\section{References}

1. Faragó, P.; Cirlugea, M.; Hintea, S. A Novel Smart-Shoe Architecture for Podiatric Monitoring. In Proceedings of the 43rd International Conference on Telecommunications and Signal Processing (TSP), Milan, Italy, 7-9 July 2020; pp. 180-183. [CrossRef]

2. Kendal, F.P.; Kendal McCreary, E.; Provance, P.G.; Rodgers, M.M.; Romani, W.A. Muscles: Testing and Testing and Function with Posture and Pain, 5th ed.; Lippincott Williams \& Wilkins: Baltimore, MD, USA, 2005.

3. Farago, M.; Pop, S. Kinetotherapy Evaluation Methods and Techniques (Original in Romanian: Metode și Tehnici de Evaluare în Kinetoterapie); Editura Universități din Oradea: Oradea, Romania, 2008.

4. Ho, I.J.; Hou, Y.Y.; Yang, C.H.; Wu, W.L.; Chen, S.K.; Guo, L.Y. Comparison of Plantar Pressure Distribution between Different Speed and Incline During Treadmill Jogging. J. Sports Sci. Med. 2010, 9, 154-160. [PubMed]

5. Wafai, L.; Zayegh, A.; Woulfe, J.; Aziz, S.M.; Begg, R. Identification of Foot Pathologies Based on Plantar Pressure Asymmetry. Sensors 2015, 15, 20392-20408. [CrossRef] [PubMed]

6. Shu, L.; Hua, T.; Wang, Y.; Li, Q.; Feng, D.; Tao, X. In-shoe plantar pressure measurement and analysis system based on fabric pressure sensing array. IEEE Trans. Inf. Technol. Biomed. 2010, 14, 767-775. [CrossRef] [PubMed]

7. Wei, Q.; Lu, W.; Fu, Z.; Lu, S. A new system for foot pressure measurement and gait analysis. Chin. J. Biomed. Eng. 2000, 19, 32-40.

8. Maier, L. Portable Plantar Pressure Monitoring System Implemented with Arduino UNO (Original in Romanian: Sistem Portabil de Monitorizare a Presiunii Plantare Implementat cu Arduino UNO). Diploma Thesis, Technical University of Cluj-Napoca, Cluj-Napoca, Romania, 2019.

9. $\quad$ Elvitigala, D.S.; Matthies, D.J.C.; David, L.; Weerasinghe, C.; Nanayakkara, S. GymSoles: Improving Squats and Dead-Lifts by Visualizing the User's Center of Pressure. In Proceedings of the 2019 CHI Conference on Human Factors in Computing Systems (CHI'19), Glasgow, UK, 4-9 May 2019; Paper 174; pp. 1-12. [CrossRef]

10. Karadsheh, M. Orthobullets-Gait Cycle. Available online: https://www.orthobullets.com/foot-and-ankle/7001/gait-cycle (accessed on 25 November 2020).

11. Alamdari, A.; Krovi, V.N. Chapter Two-A Review of Computational Musculoskeletal Analysis of Human Lower Extremities In Human Modeling for Bio-inspired Robotics: Mechanical Engineering in Assistive Technologies; Ueda, J., Kurita, Y., Eds.; Academic Press: San Diego, CA, USA, 2017; pp. 37-73. ISBN 978-0-12-803137-7. [CrossRef]

12. Bonnefoy, A.; Armand, S. Normal Gait. In Orthopedic Management of Children with Cerebral Palsy: A Comprehensive Approach; Canavesse, F., Deslandes, J., Eds.; Nova Science Publishers: Hauppauge, NY, USA, 2015; pp. 199-213. ISBN 978-1-63483-318-9.

13. Ivanov, K.; Mei, Z.; Lubich, L.; Guo, N.; Xile, D.; Zhao, Z.; Omnisore, O.M.; Ho, D.; Wang, L. Design of a Sensor Insole for Gait Analysis. In Intelligent Robotics and Applications. ICIRA 2019. Lecture Notes in Computer Science; Yu, H., Liu, J., Liu, L., Ju, Z., Liu, Y., Zhou, D., Eds.; Springer: Cham Switzerland, 2019; Volume 11743, pp. 433-444. ISBN 978-3-030-27537-2. [CrossRef]

14. Cho, H. Design and Implementation of a Lightweight Smart Insole for Gait Analysis. In Proceedings of the 2017 IEEE Trustcom/BigDataSE/ICESS, Sydney, NSW, Australia, 1-4 August 2017; pp. 792-797. [CrossRef]

15. Aqueveque, P.; Osorio, R.; Pastene, F.; Saavedra, F.; Pino, E. Capacitive Sensors Array for Plantar Pressure Measurement Insole fabricated with Flexible PCB. In Proceedings of the 40th Annual International Conference of the IEEE Engineering in Medicine and Biology Society (EMBC), Honolulu, HI, USA, 18-21 July 2018; pp. 4393-4396. [CrossRef]

16. Kramer, M.; du Randt, R.; Venter, D. Dynamic plantar pressure profiles of South African university students. S. Afr. J. Sports Med. 2015, 27, 4-11. [CrossRef]

17. Honeine, J.L.; Schiepati, M.; Gagey, O.; Do, M.C. The Functional Role of the Triceps Surae Muscle during Human Locomotion. PLoS ONE 2013, 8, 52943. [CrossRef]

18. Qaqish, J.; McLean, S. Foot Type and Tibialis Anterior Muscle Activity during Stance Phase of Gait. Int. J. Physiother. Rehabil. 2010, 1, 19-29.

19. Lenhart, R.L.; Francis, C.A.; Lenz, A.L.; Thelen, D.G. Empirical evaluation of gastrocnemius and soleus function during walking. J. Biomech. 2014, 47, 2969-2974. [CrossRef]

20. Orendurff, M.S.; Aiona, M.D.; Dorociak, R.D.; Pierce, R.A. Length and force of the gastrocnemius and soleus during gait following tendo Achilles lengthenings in children with equinus. Gait Posture 2002, 15, 130-135. [CrossRef]

21. Krewer, C.; Bergmann, J.; Gräfrath, P.C.; Jahn, K. Influence of foot position on static and dynamic standing balance in healthy young adults. Hear. Balance Commun. 2018, 16, 208-214. [CrossRef]

22. Barati, A.H.; Bagheri, A.; Azimi, R.; Darchini, M.A.; Nik, H.N. Comparison balance and footprint parameters in normal and overweight children. Int. J. Prev. Med. 2013, 4, 92-97.

23. AlAbdulwahab, S.S.; Kachanathu, S.J. Effects of body mass index on foot posture alignment and core stability in a healthy adult population. J. Exerc. Rehabil. 2016, 12, 182-187. [CrossRef] [PubMed]

24. Aurichio, T.R.; Rebelatto, J.R.; de Castro, A.P. The relationship between the body mass index (BMI) and foot posture in elderly people. Arch. Gerontol. Geriatr. 2011, 52, 89-92. [CrossRef] [PubMed]

25. Hawke, F.; Rome, K.; Evans, A.M. The relationship between foot posture, body mass, age and ankle, lower-limb and whole-body flexibility in healthy children aged 7 to 15 years. J. Foot Ankle Res. 2016, 9, 14. [CrossRef]

26. Carvalho, C.E.; da Silva, R.A.; Gil, A.W.; Oliveira, M.R.; Nascimento, J.A.; Pires-Oliveira, D.A. Relationship between foot posture measurements and force platform parameters during two balance tasks in older and younger subjects. J. Phys. Ther. Sci. 2015, 27, 705-710. [CrossRef] 
27. Timotius, I.K.; Canneva, F.; Minakaki, G.; Pasluosta, C.; Moceri, S.; Casadei, N.; Riess, O.; Winkler, J.; Klucken, J.; von Hörsten, S.; et al. Dynamic footprint based locomotion sway assessment in $\alpha$-synucleinopathic mice using Fast Fourier Transform and Low Pass Filter. J. Neurosci. Methods 2018, 296, 1-11. [CrossRef]

28. Ellenbecker, T.S.; Aoki, R. Step by Step Guide to Understanding the Kinetic Chain Concept in the Overhead Athlete. Curr. Rev. Musculoskelet. Med. 2020, 13, 155-163. [CrossRef]

29. Giacomozzi, C.; Caravaggi, P.; Stebbins, J.A.; Leardini, A. Integration of Foot Pressure and Foot Kinematics Measurements for Medical Applications. In Handbook of Human Motion; Müller, B., Wolf, S., Eds.; Springer: Cham, Switzerland, 2016 ; pp. 1-22. ISBN 978-3-319-30808-1. [CrossRef]

30. Carson, M.C.; Harrington, M.E.; Thompson, N.; O'Connor, J.J.; Theologis, T.N. Kinematic analysis of a multi-segment foot model for research and clinical applications: A repeatability analysis. J. Biomech. 2001, 34, 1299-1307. [CrossRef]

31. Balsdon, M.E.R.; Dombroski, C.E. Reliability of a multi-segment foot model in a neutral cushioning shoe during treadmill walking. J. Foot Ankle Res. 2018, 11, 60. [CrossRef]

32. Schallig, W.; van den Noort, J.C.; McCahill, J.; Stebbins, J.; Leardini, A.; Maas, M.; Harlaar, J.; van der Krogt, M.M. Comparing the kinematic output of the Oxford and Rizzoli Foot Models during normal gait and voluntary pathological gait in healthy adults. Gait Posture 2020, 82, 126-132. [CrossRef]

33. Leardini, A.; Benedetti, M.G.; Berti, L.; Bettinelli, D.; Nativo, R.; Giannini, S. Rear-foot, mid-foot and fore-foot motion during the stance phase of gait. Gait Posture 2007, 25, 453-462. [CrossRef] [PubMed]

34. Simon, J.; Doederlein, L.; McIntosh, A.S.; Metaxiotis, D.; Bock, H.G.; Wolf, S.I. The Heidelberg foot measurement method: Development, description and assessment. Gait Posture 2006, 23, 411-424. [CrossRef] [PubMed]

35. Nicholson, K.; Church, C.; Takata, C.; Niiler, T.; Chen, B.P.; Lennon, N.; Sees, J.P.; Henley, J.; Miller, F. Comparison of threedimensional multi-segmental foot models used in clinical gait laboratories. Gait Posture 2018, 63, 236-241. [CrossRef] [PubMed]

36. Stebbins, J.; Giacomozzi, C.; Theologis, T. Correlation between plantar pressure and Oxford Foot Model kinematics. J. Foot Ankle Res. 2008, 1, 1-2. [CrossRef]

37. Giacomozzi, C.; Stebbins, J.A. Anatomical masking of pressure footprints based on the Oxford Foot Model: Validation and clinical relevance. Gait Posture 2017, 53, 131-138. [CrossRef]

38. Wank, V.; Frick, U.; Schmidtbleicher, D. Kinematics and electromyography of lower limb muscles in overground and treadmill running. Int. J. Sports Med. 1998, 19, 455-461. [CrossRef]

39. Prasad, N.K.; Coleman Wood, K.A.; Spinner, R.J.; Kaufman, K.R. Foot and Ankle Kinematics and Dynamic Electromyography: Quantitative Analysis of Recovery from Peroneal Neuropathy in a Professional Football Player. J. Surg. Orthop. Adv. 2016, $25,180-186$.

40. MIKROE Time-saving Embedded Tools-EMG Click Datasheet. Available online: https:/ / www.mikroe.com/emg-click (accessed on 25 November 2020).

41. Narwaria, R.P.; Verma, S.; Singhal, P.K. Removal of Baseline Wander and Power Line Interference from ECG Signal—A Survey Approach. Int. J. Electron. Eng. 2011, 3, 107-111.

42. Hung, C.-C.; Halonen, I.; Ismail, M.; Porra, V. Micropower CMOS Gm-C Filters for Speech Signal Processing. In Proceedings of the 1997 IEEE International Symposium on Circuits and Systems, Hong Kong, China, 9-12 June 1997; Volume 3, pp. $1972-1975$.

43. Mills, K.R. The basics of electromyography. J. Neurol. Neurosurg. Psychiatry 2005, 76, 32-35. [CrossRef]

44. Faragó, P.; Groza, R.; Hintea, S. High Precision Activity Tracker Based on the Correlation of Accelerometer and EMG Data. In Proceedings of the 42nd International Conference on Telecommunications and Signal Processing (TSP), Budapest, Hungary, 1-3 July 2019; pp. 428-431. [CrossRef]

45. Al-Angari, H.M.; Kanitz, G.; Tarantino, S.; Cipriani, C. Distance and mutual information methods for EMG feature and channel subset selection for classification of hand movements. Biomed. Signal Process. Control 2016, 27, 24-31. [CrossRef]

46. Balbinot, A.; Favieiro, G. A Neuro-Fuzzy System for Characterization of Arm Movements. Sensors 2013, 13, 2613-2630. [CrossRef] [PubMed]

47. Faragó, P.; Groza, R.; Ivanciu, L.; Hintea, S. A Correlation-based Biometric Identification Technique for ECG, PPG and EMG. In Proceedings of the 42nd International Conference on Telecommunications and Signal Processing (TSP), Budapest, Hungary, 1-3 July 2019; pp. 716-719. [CrossRef]

48. Nazmi, N.; Abdul Rahman, M.A.; Yamamoto, S.; Ahmad, S.A.; Zamzuri, H.; Mazlan, S.A. A Review of Classification Techniques of EMG Signals during Isotonic and Isometric Contractions. Sensors 2016, 16, 1304. [CrossRef] [PubMed]

49. Zhang, Y.; Li, P.; Zhu, X.; Su, S.W.; Guo, Q.; Xu, P.; Yao, D. Extracting time-frequency feature of single-channel vastus medialis EMG signals for knee exercise pattern recognition. PLoS ONE 2017, 12, 0180526. [CrossRef] [PubMed]

50. Rabbi, M.F.; Ghazali, K.H.; Ahamed, N.U.; Sikandar, T. Time and frequency domain features of EMG signal during Islamic prayer (Salat). In Proceedings of the IEEE 13th International Colloquium on Signal Processing \& its Applications (CSPA), Batu Ferringhi, Malaysia, 10-12 March 2017; pp. 139-143. [CrossRef]

51. Munteanu, M.; Rusu, C.; Moga, D.; Moga, R.; Tont, G. EMG Signals Case Study: A Time and Frequency Domain Analysis. In IFMBE Proceedings book series, Proceedings of the International Conference on Advancements of Medicine and Health Care through Technology, Cluj-Napoca, Romania, 29 August-2 September 2011; Vlad, S., Ciupa, R.V., Eds.; Springer: Berlin/Heidelberg, Germany, 2011; Volume 36, pp. 202-205. [CrossRef]

52. Marple, S.L., Jr. Digital Spectral Analysis, 2nd ed.; Dover Publications: Mineola, NY, USA, 2019; ISBN 978-048-6780-52-8. 
53. Park, S.; Choi, H.; Ryu, K.; Kim, S.; Kim, Y. Kinematics, kinetics and muscle activities of the lower extremity during the first four steps from gait initiation to the steady-state walking. J. Mech. Sci. Technol. 2009, 23, 204-211. [CrossRef]

54. Di Giulio, I.; Maganaris, C.N.; Baltzopoulos, V.; Loram, I.D. The proprioceptive and agonist roles of gastrocnemius, soleus and tibialis anterior muscles in maintaining human upright posture. J. Physiol. 2009, 587, 2399-2416. [CrossRef] [PubMed]

55. Farago, P.; Groza, R.; Hintea, S.; Soser, P. A Programmable Biopotential Aquisition Front-end with a Resistance-free Currentbalancing Instrumentation Amplifier. Adv. Electr. Comput. Eng. 2018, 18, 85-92. [CrossRef]

56. Yoon, S.W. Analysis of the muscular activities of the tibialis anterior and gastrocnemius muscles in functional reach. J. Phys. Ther. Sci. 2017, 29, 851-853. [CrossRef] 